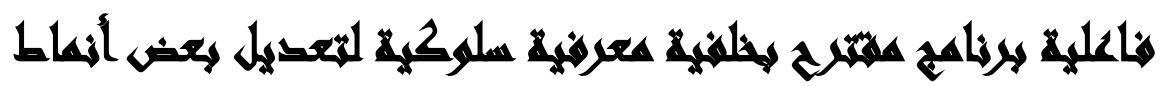

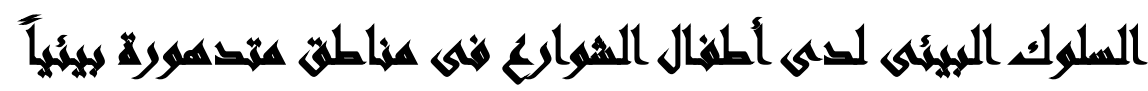

[?]

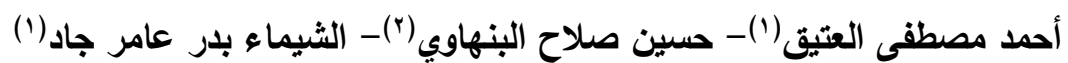

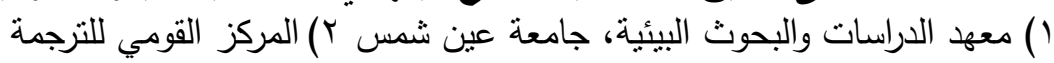

\section{المستخلص}

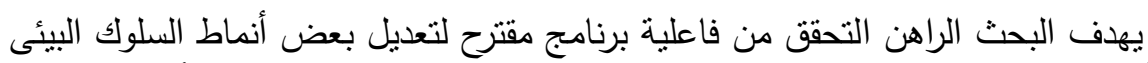

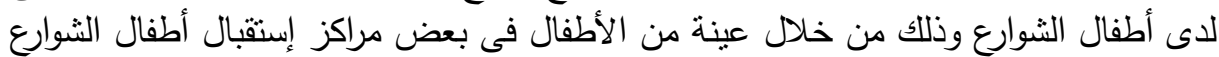

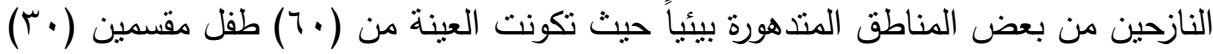

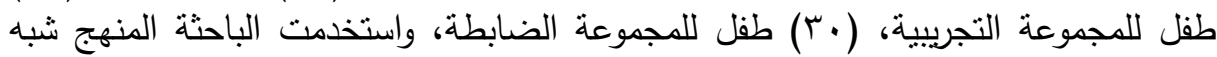

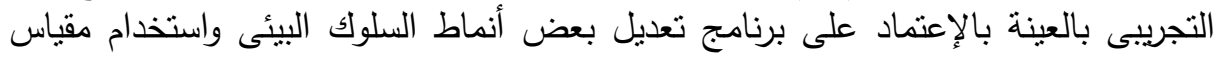

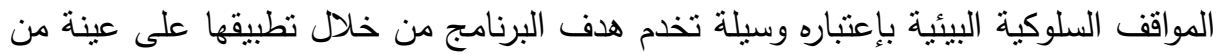
الأطفال قبل وبعد تطبيق البرنامج، بالإضافة إلى استخدام مقياس التدهور البيأئى، مقياس

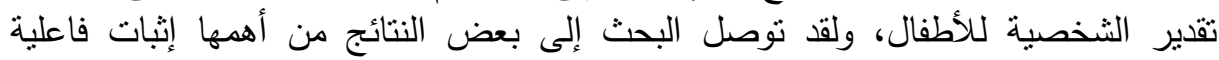

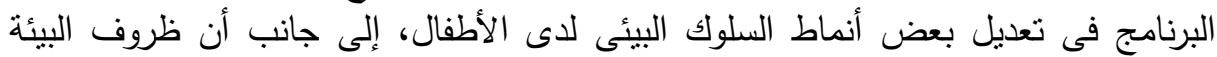

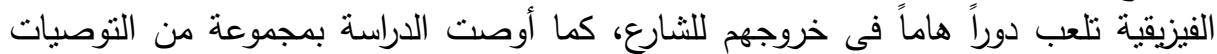

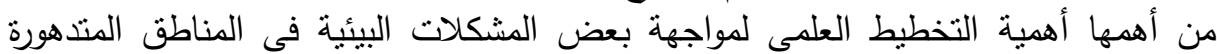

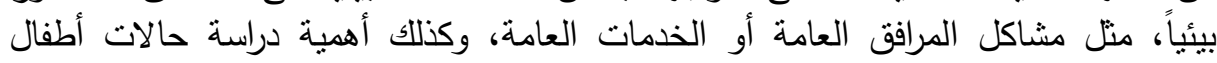

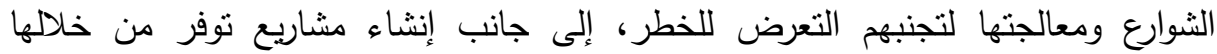
احتياجات الأطفال الذين تسربوا من التعليم، وكذللك ضرورة وضع تصور لانئن لحل المشكلات

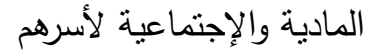

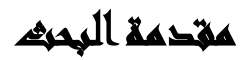

يعد مجال دراسة أطفال الثوارع من المجالات الهامة التى استحوذت على فكر الباحثني فى كافة المجالات وقد تتاولته الدراسات من عدة مداخل مختلفة (كالمدخل السيكولوجى،

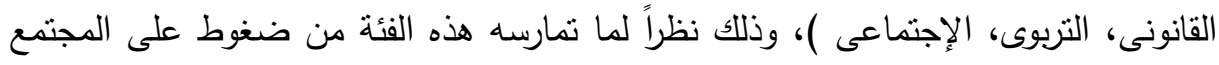
بكافة قطاعاته، حيث أثنارت كثثر من تقارير التتمية البشرية إلى ارتفاع أعداد أطفال الثوارع 
بصورة ملحوظة كما أثنارت إلى المخاطر التى يمكن أن تتعرض لها المجتمعات التى تعانى

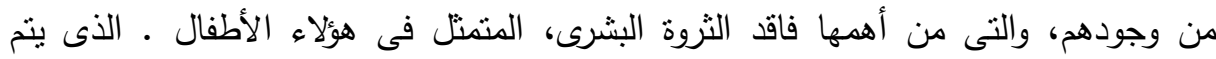

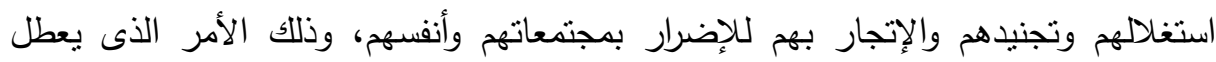

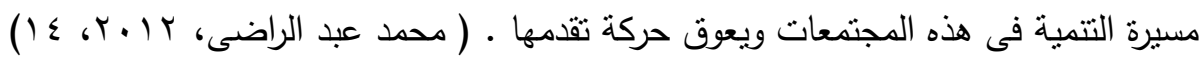

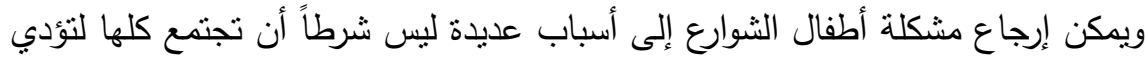

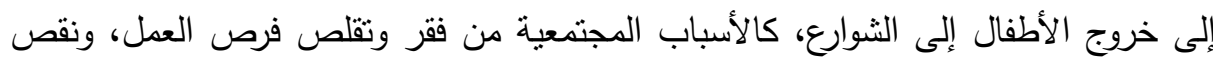
المساعدات للأسر المحتاجة، والبطالة، والهجرة من الريف إلى المدينة، والأسباب الأسرية

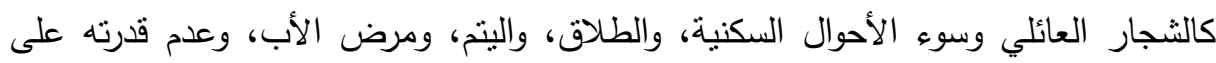

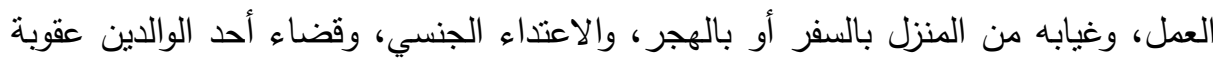

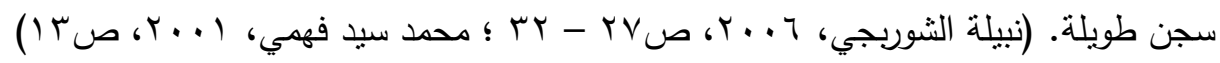
ويعتبر الفقر بأثكاله المختلفة سواء المادي الذي بعني قلة الذخل، وعدم كفايته لتوفير

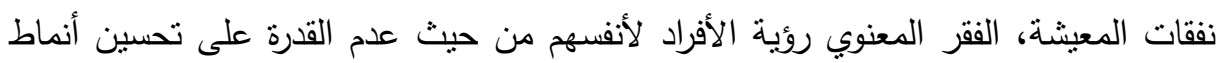

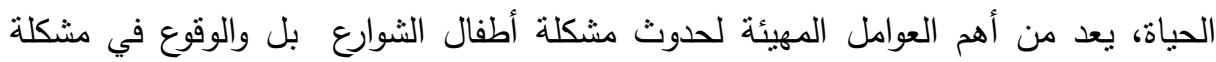
الاتجار بهولاء الأطفال أحياناً. تلعب الأوضاع والظروف الأسرية دوراً مهماً وأساسياً في انتشار مشكلة أطفال الثوارع، بهان

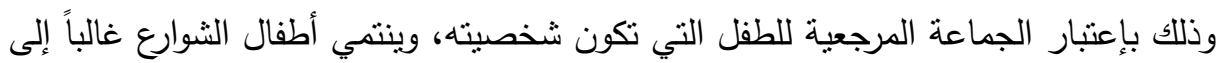

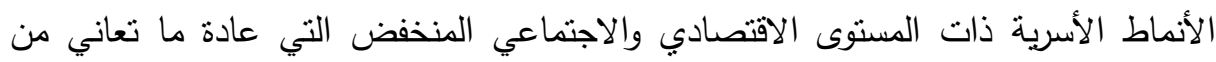
انخفاض الدخل والتعليم والوعي التربوي والقصور في الرعاية الاجتماعية والصحية للطفل.

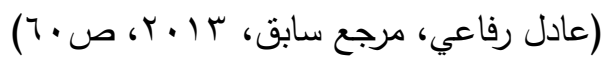

إن أهم خاصية في بيئة الطفل عموماً هي العائلة لأنها تزوده بالمأوى الذي ينعلم فيه الطفل كيف يعيش كعضو في المجتمع كأسرة كبيرة والذي فيه يمنح الوالدان قليلا من التوجيه

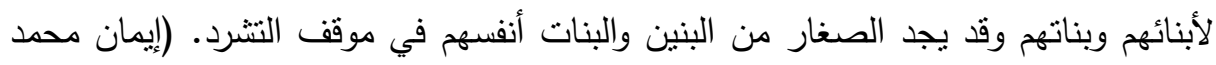

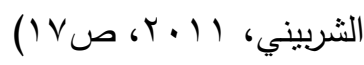


يترتب على حياة الثارع الكثير من الظواهر السلبية والضارة لكل من الأطفال والمجتمع

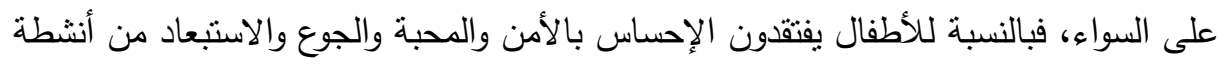

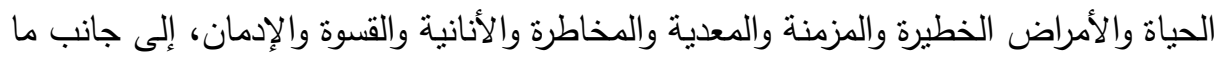
يتعرض له الأطفال من العنف والاستغلال الجنسي سواء من الأفراد أو العصابات أو الكبار

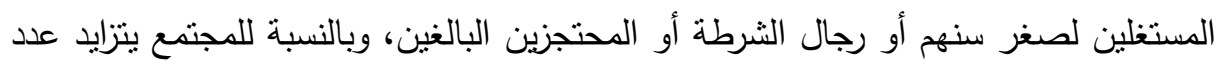

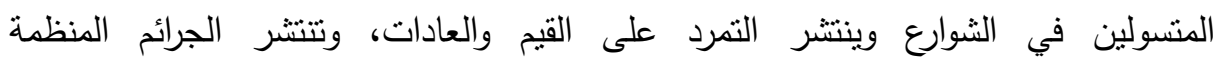

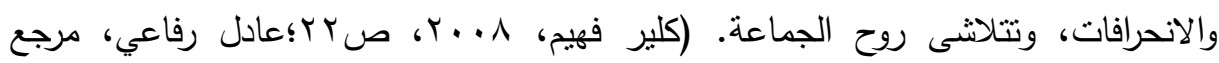

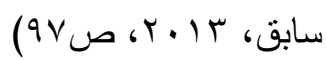
كما تعتبر مشكلة التجمعات العشوائية والمتدهورة بيئياً من أهم الظواهر السلبية التى لها

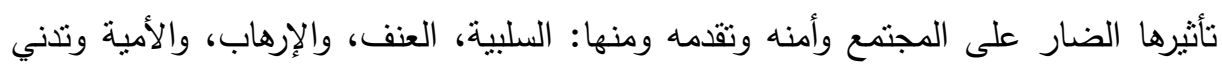

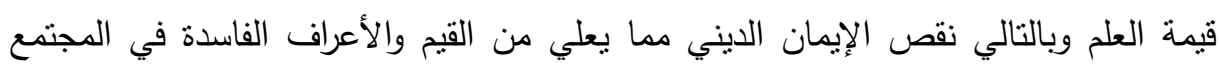

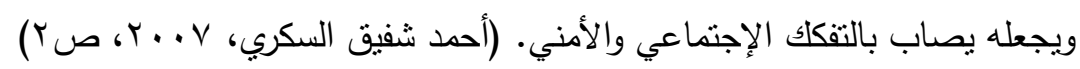

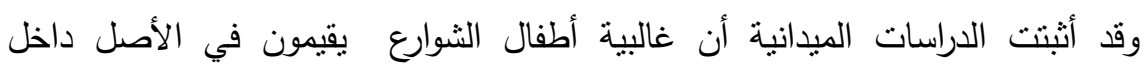

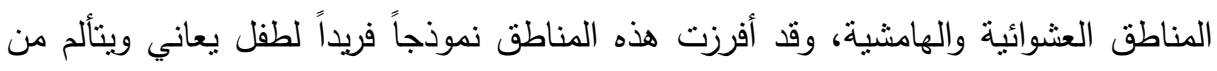

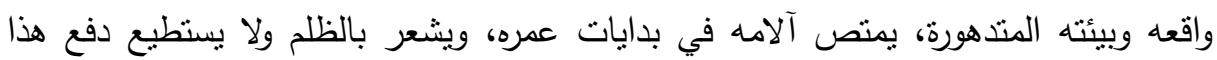

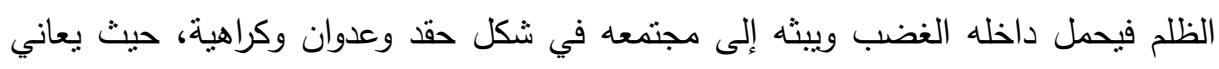

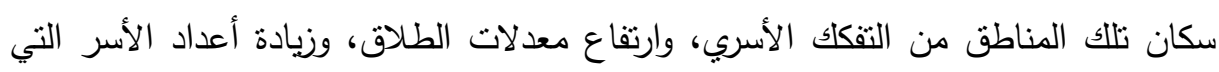

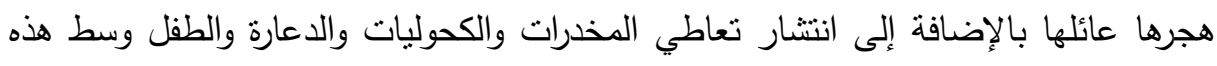
البيئة يعاني من سوء الرعاية، والعمل في سن مبكر ، والاختلاط بالمنحرفين والمجرمين ورفاق

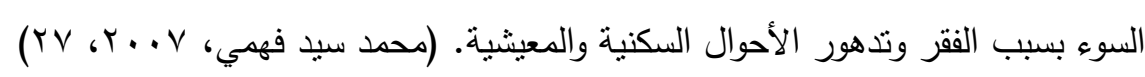

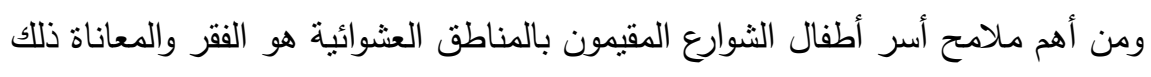

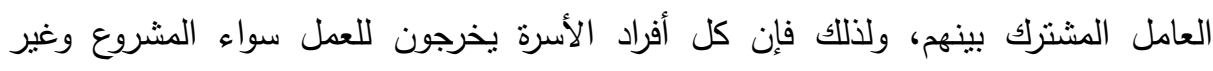
المشروع من أجل لقمة العيش، فمنهم من يعمل في إحدى الورش، ومنهم من يتسول في الثوارع، ومنهم من يحترف السرقة والنصب وتجارة المخدرات، وبالرغم من نتوع الدخل إلا أنهم 
ينفقونه بطريقة غير سليمة، ولا يهتمون بمظهرهم أو صحتهم أو مكان إقامتهم، كما ينتشر

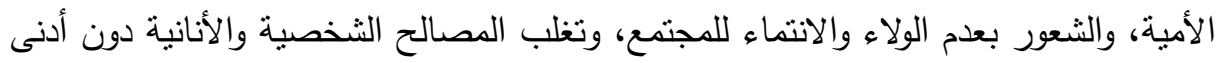

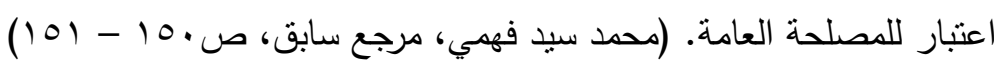

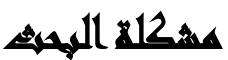

تعد مشكلة أطفال الثوارع من أهم المشكلات الإجتماعية التى يعانى منها العالم بأسره،

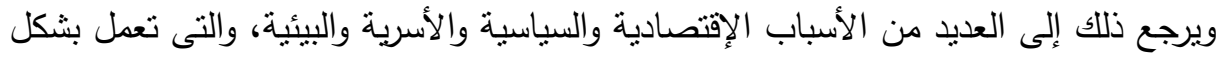
متفاعل لتهيئة المناخ العام لنموها وتطورها، ولقد نمت هذه المشكلة فى العديد من الدول محلياً وعالمياً

وتعانى مصر من ظاهرة أطفال الثوارع التى تشمل عمالة الأطفال والمتشردين والمتسولين، فتحولت من مشكلة على نطاق ضيق إلى ظاهرة واسعة جداً تتضمن المخاطر المصاحبة لها وتكثف عن قصور السياسات للحد منها، وكان أول المتضررين الأطفال وهم

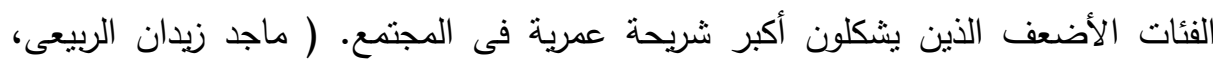
(100, r...)

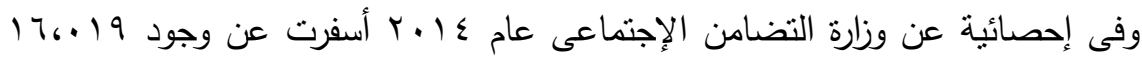

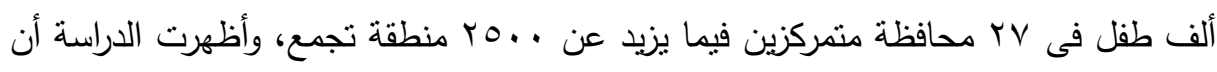

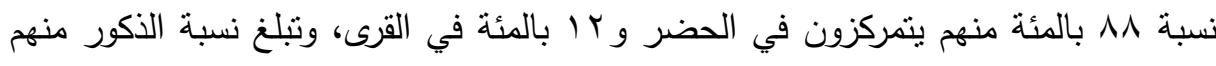

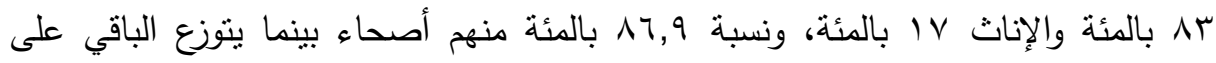

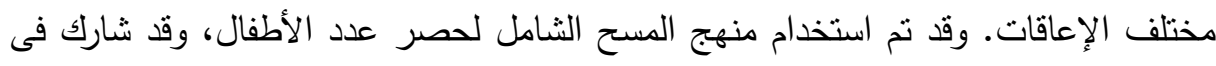
إجراء البحث ما يزيد عن .... بـ باحث ومثرف من الوزارة والمركز القومى للبحوث الإجتماعية والجنائية والمجلس القومى للأمومة والطفولة وبعض الباحثنين بالجمعيات الأهلية العاملة فى هذه المجال، وكثفت أن استراتيجية الوزارة في تتفيذ برنامج متكامل لرعاية أطفال

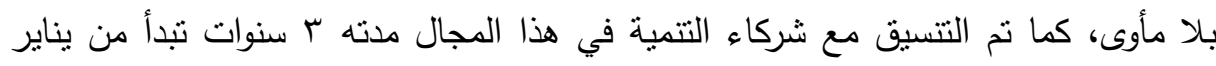

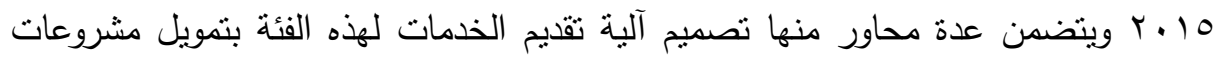


للجمعيات العاملة في هذا المجال، وتطوير قدرات الوزارة المتعلقة بقضية الأطفال بلا مأوى من وقاية وحماية وتأهيل ودمج، حيث نم تحديد الخدمات في المناطق المستهدفة - الجاذبة

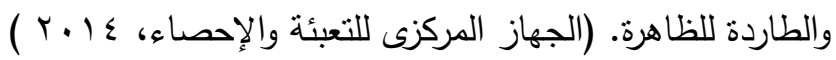

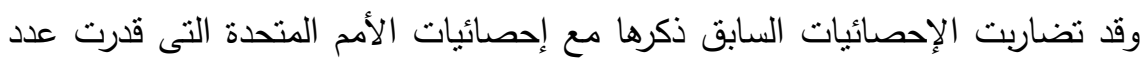

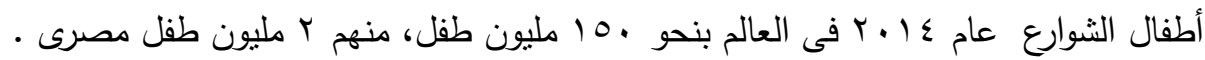
وقد أقر مركز معلومات دعم واتخاذ القرار التابع لمجلس الوزراء بعدم وجود إحصائيات نهائية واضحة عن أطفال الثوارع، ويوصي بضرورة الاهتمام بهذه الظاهرة التي تعد الحلقة

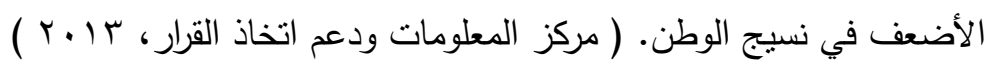
وتوضح العديد من الدراسات ارتباط مشكلة أطفال الثوارع بالعديد من المتغيرات ومنها ارتباطها ببعض الخصائص النفسية مثل الوحدة النفسية وتتشل: نتيجة لـشاعر اليأس والعجز والاتجاهات السالبة ونقص الدافعية للتغير والقلق وانخفاض الروح المعنوية بالإضافة إلى لى لئه (ارتباطه بالعدوان مما يؤدي إلى السلوك الإجرامي أو تكون الثخصية السيكوباتية المضادة

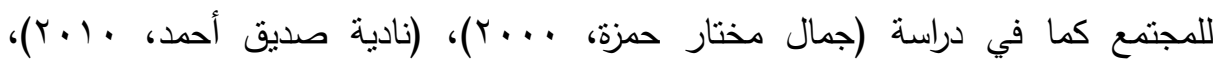

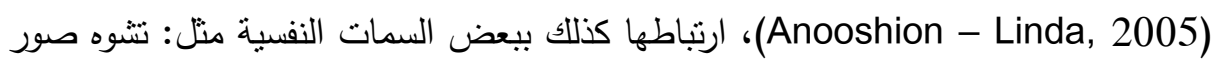
الذات، الشعور بتقدير الذات المنخفض وعدم حب الآخرين له وذللك منل دراسة (رانده فتحي لـاني

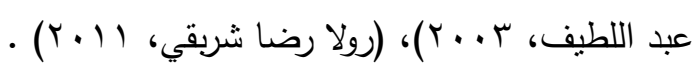
بينما اهتمت بعض الدراسات الآخرى ذات الصلة بالمناطق المتدهورة بيئياً وفى ارتباطها بمشكلة أطفال الثوارع مثل بعض الدراسات التى هدفت إلى التعرف على المتغيرات

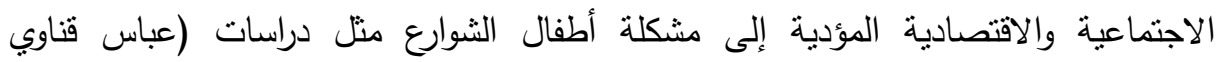

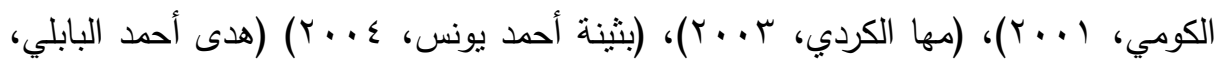

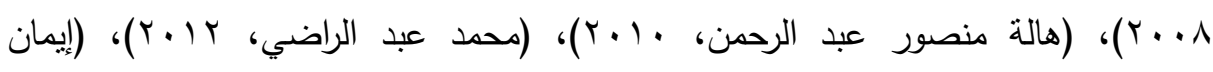

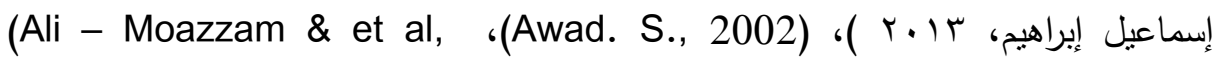


ومن هذا المنطلق جاء الاهتمام بهذا الموضوع إحساساً بالمشكلة لمعرفة أسبابها وإعداد برنامج لتحسين بعض السلوكيات التى قد تساهم فى تعديل السلوك البيئى لدى هؤلاء الأطفال،

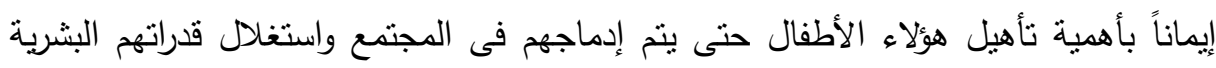

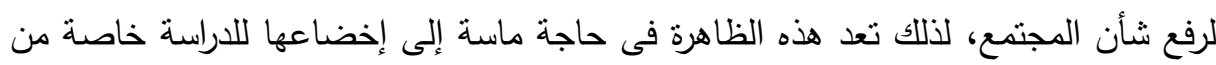

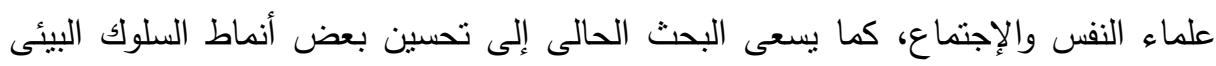
لدى هذه الفئة، بإعتباره يتأثر بعدة عوامل تتحدد على أساسها شخصية الطفل وسلوكياته تجاه

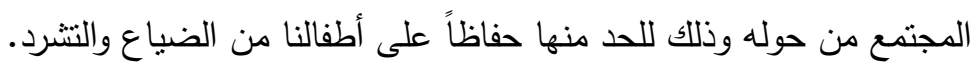
ويمكن صياغة إثكالية البحث فى ضوء التساؤلات الآتية :

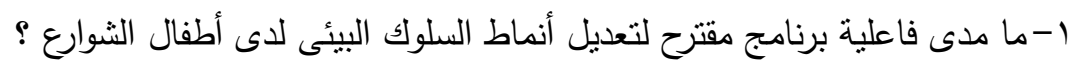

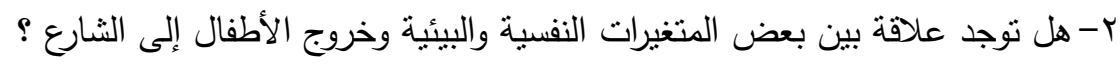

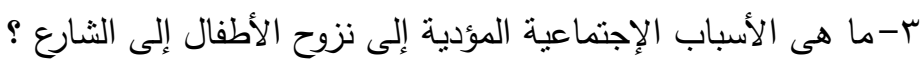
النظرية الموجهة لموضوع البحث: ( النظرية المعرفية السلوكية ): تعد نتاج تداخل ثلاث مدارس هي العلاج السلوكي، العلاج المعرفي، علم النفس الاجتماعي المعرفي، وترتكز على إطار نظرية التعلم الاجتماعي لباندورا، حيث يرى أن عملية التعليم تتم من خلال العل

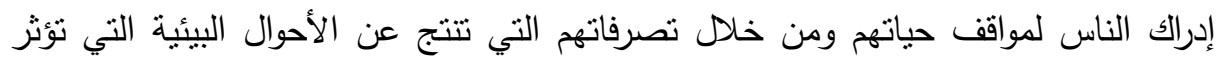

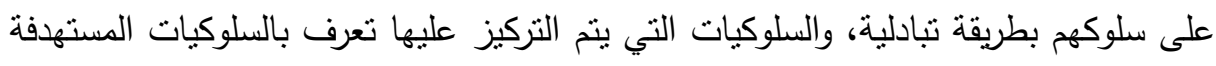
وتبدأ بوقائع السلوك التي تسبق المشكلة والأحداث التي تليها تسمى النتائج ويكون استخدام

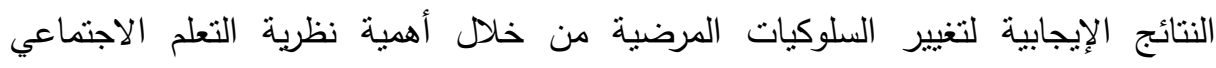
والخبرات التي تتتج عن السلوك يمكن أن تعمل على تجديد ما يفكر فيه الفرد وما يمكن أن الن النيه

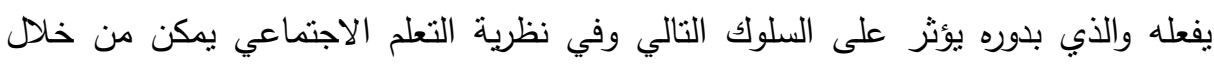
الأفكار والمشاعر توضيح السلوك. (Marlene. G, Cooper \& Joongranuei Lesser, 


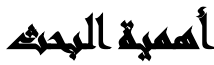

1- أهية مرحلة الطفولة بإعتبار أن أى خلل فى تهيئة الظروف الاجتماعية والنفسية السوية التى يعيشها الطفل هى المؤثرة بالسلب فى سلوكياته بشكل عام وسلوكه البيئى بشكل

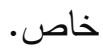

r- تفاقم مشكلة أطفال الثوارع وما يتعلق بها من متغيرات ( نفسية وأسرية وتعليمية وإقتصادية

$$
\text { وبيئية ) وما ينتج عنها من آثار سلبية على الفرد والمجتمع بأسره. }
$$

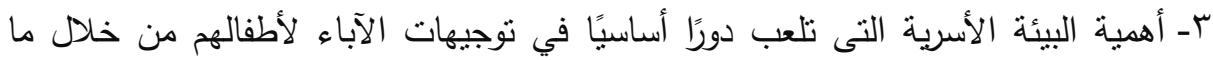

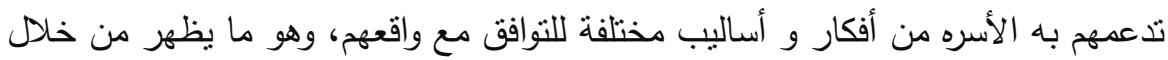
توجهات الأطفال وسلوكياتهم الظاهرة منها والباطنة. ع- الإهتمام بالظروف البيئية القاسية والمخاطر النفسية والإجتماعية الناتجة عنها وضرورة ولهابة

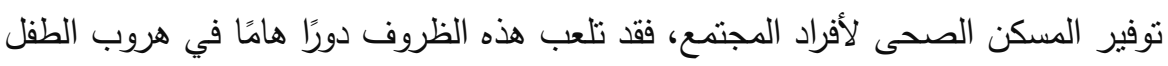

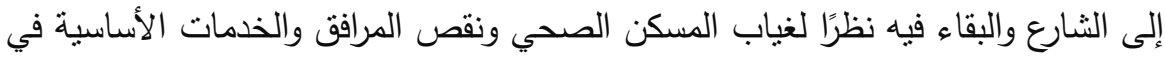

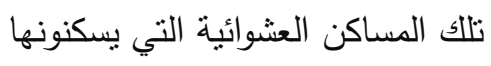

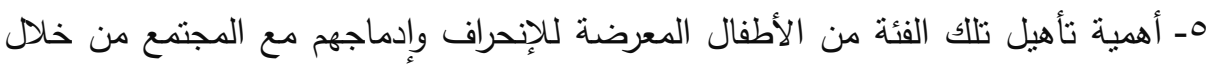

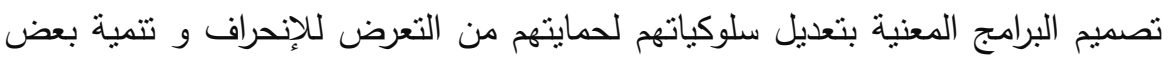

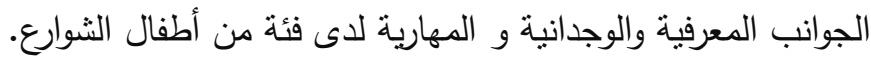

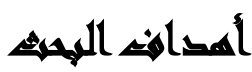

يسعى البحث إلى تحقيق مجموعة من الأهداف يمكن تقسيمها إلى:

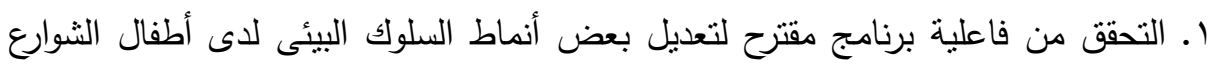

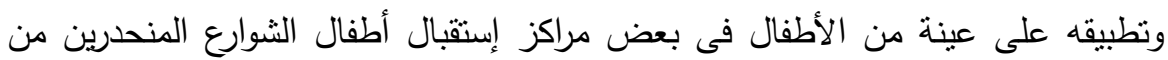

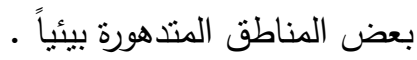
r. الكثف عن طبيعة العلاقة بين بعض المتغيرات النفسية والبيئية وبين خروج الأطفال إلى بلى الثوارع. 
r. إكساب بعض القائمين على رعاية هؤلاء الأطفال فى المؤسسات بعض الطرق اللازمة لتعديل السلوك البيئى لديهم • البهن ع. التعرف على فئة أطفال الشوارع وأهم خصائصهم وسماتهم الثخصية والأسباب المؤدية إلى تزايد المشكلة إلى جانب رصد التداعيات والآثار السلبية الناجمة عن هذه المشكلة.

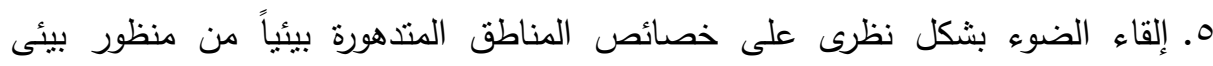

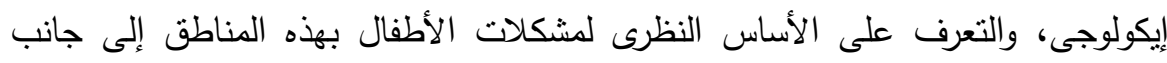

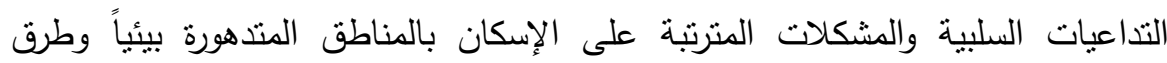
مواجنها وتأثيرها على خروج الأطفال إلى الثارع.

\section{هغرون الهAهA}

1-توجد فروق ذات دلالة احصائية بين منوسط درجات أطفال المجموعة التجريبية على أبعاد مقياس المواقف السلوكية البيئية فى القياسين (القبلى والبعدى) لصالح القياس البعدى. r-توجد فروق ذات دلالة احصائية بين متوسطي درجات المجموعة التجريبية والمجموعة

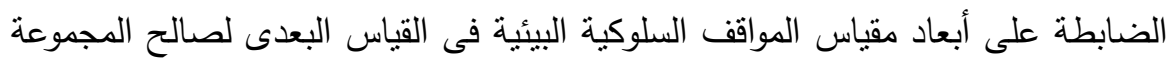

$$
\text { التجريبية. }
$$

r-توجد علاقة ارتباطية بين بعض سمات تقدير الثخصية لدى الأطفال وخروجهم إلى الشارع. ع-توجد علاقة ارتباطية بين الظروف البيئية القاسية (التدهور البيئى) وخروج الطفل إلى الثارع.

\section{هناسمبر المهAه}

أولاً: تعريف برنامج معرفى سلوكى: يرى ( رأفت عبد الرحمن، ؟ ... ) أن المدخل

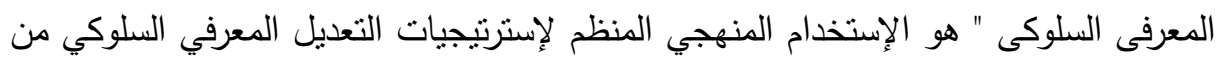

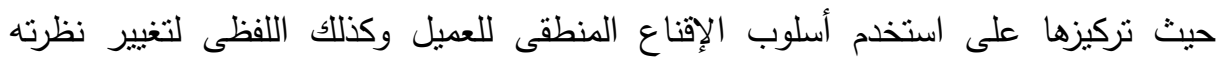


للأشياء مما يساعد على تغيير المعارف والانفعالات والسلوكيات غير التوافقية" (رأفت عبد

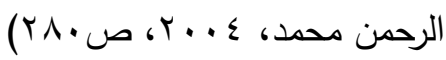

ويعرف بأنه "ثكل مركب من أشكال العلاج النفسي، والذي ينتج عن تجاوب بين إستراتيجيات تعديل السلوك والتي تتتمي إلى العلوم السلوكية (أو التحليل السلوكي) والعلاج

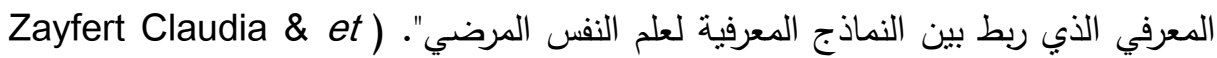
(al, 2006, p3 ثانياً: تعريف السلوك البيئى: يعرف (Nerga \& Manning) السلوك البيئي بأنه "أب فعل أو تصرف فردي أو جماعي موجه مباشرة لعلاج أو حل القضايا والمشكلات البيئية". (Nerga \& Manning, 1997, p15) أنشارت "ماجدة السيد عبيد" أن تعديل السلوك تعتبر "عملية محو تعلم وإعادة تعلم، وتتضمن عملية محو تعلم السلوك غير المرغوب فيه وذلك بالعمل على إطفاء هذا السلوك،

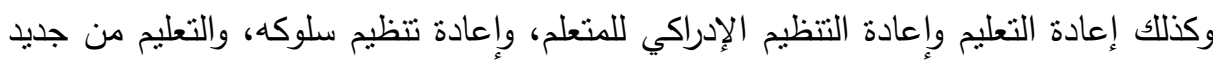

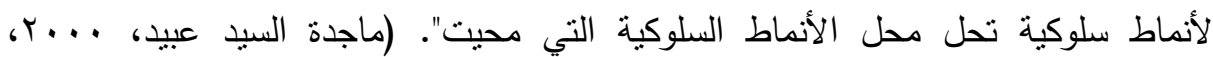
عالمياً: عرفت الأمم المتحدة United Nation أطفال الشوارع (910) بأنهم: "الأولاد والبنات الذين أصبح الثارع بمعناه الواسع والذي يتضمن الثوارع والحواري والمساكن المهجورة والأراضي المهملة بالنسبة لهم مكانا للإقامة ومصدرا للعيش، هؤلاء الأطفال تتقصهم الحماية والإثراف والتوجيه وغير ذلك من الأمور الكافية من قبل أشخاص كبار مسئولين". United) Nation, 1985, p. 115) محلياً: عرف المجلس القومي للطفولة والأمومة (r . . ب) طفل الثارع بأنه "ذللك الطفل الذي عجزت أسرته والمجتمع عن إثباع حاجاته الأساسية (جسمية، نفسية، ثقافية، صحية ... الخ) كنتاج لواقع اجتماعي واقتصادي تعايشه الأسرة في ظل ظروف اجتماعية شاملة. تدفع بالطفل

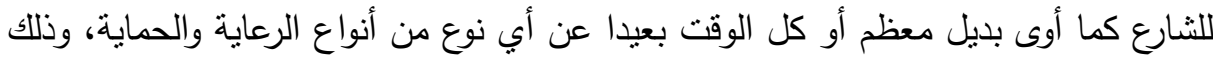

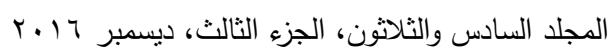


لمحاولة إثباع حاجاته من أجل البقاء، مما يعرضه للخطر والاستغلال والحرمان من الحصول على حقوقه الأساسية وقد يتعرض للمسائلة القانونية. (المجلس القومي للطفولة والأمومة،

رابعاً: المناطق المتدهورة بيئياً: عرفت المناطق المتدهورة بيئياً وفقاً لقانون التخطيط العمراني وذلك عند تحديده للأحياء بأنها: " تللك المناطق أو المساحات التي يعاني من التزاحم السكاني وتككون الغالبية العظمى من مبانيها متخلفة ومتهالكة، وكذلك المناطق أو المساحات التي تكون بعض مبانيها منخلفة وتفتقر إلى المرافق أو الخدمات الأساسية". (آمال إسماعيل

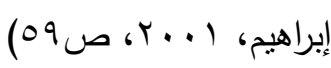

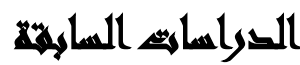

(1) دراسة بعنوان "فاعلية برنامج معرفي سلوكي لتخفيف السلبية نحو الذات والعالم

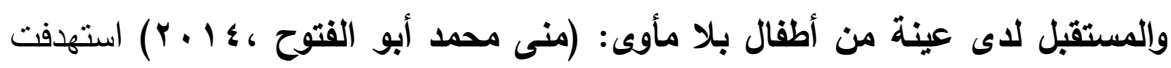

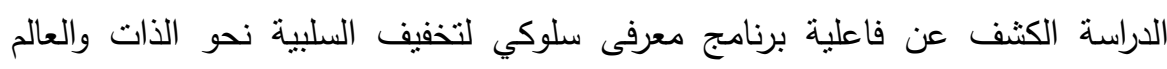
والمستقبل لاى عينة من الأطفال بلا مأوى كذلك للكثف عن استمرارية فاعلية البرنامج واستخدمت الباحثة المنهج (التجريبي) واستعانت بالأدوات : مقياس السلبية نحو الذات والعالم والمستقبل، برنامج معرفي سلوكي ) وتضمنت العينة (•r) طفلاً من الأطفال بلا

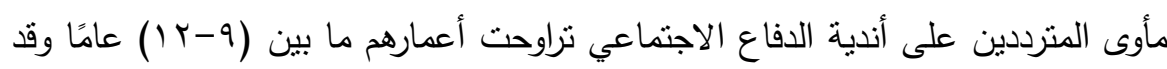

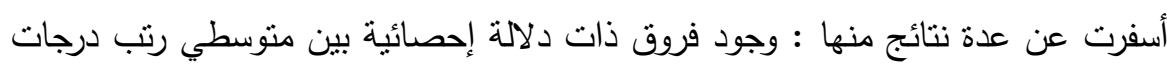

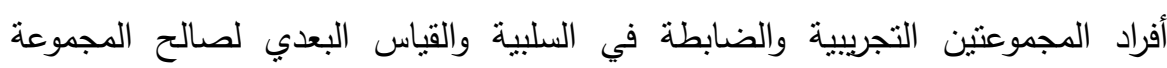
التجريبية إلى جانب عدم وجود فروق ذات دلالة إحصائية بين متوسطي رتب درجات أفئ أفراد المجموعة التجريبية في السلبية في القياسين البعدي والتتبعي.

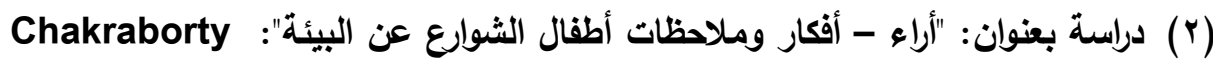
(Kabiat, 2002) هدفت الدراسة إلى محاولة التعرف على رؤية طفل الثارع عن البيئة التي يعيش فيها وملاحظاته الثخصية عن البيئة و أجريت الدراسة على عينة قوامها لئه 


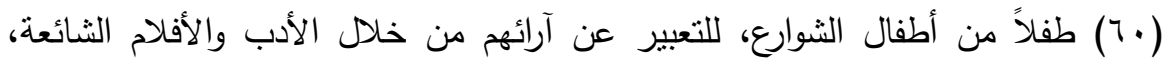

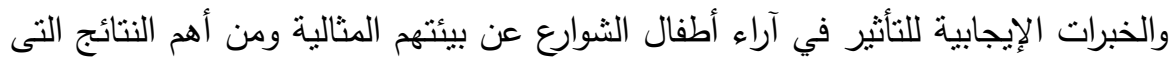

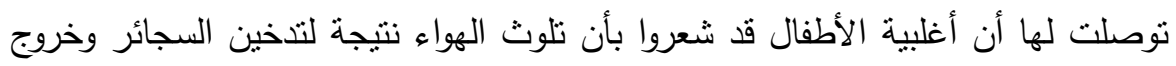

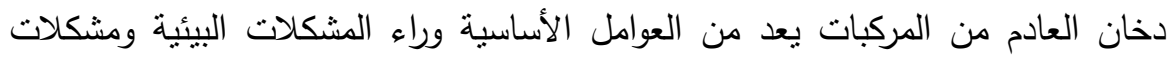

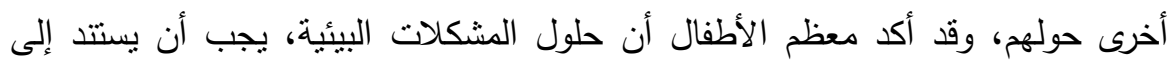
القواعد الحضارية والاجتماعية الثقافية لكي تعمل بفاعلية في المجتمع. (ץ) دراسة بعنوان: "إهمال وإساءة المعاملة واستغلال الأطفال في مدينة كييف بأوكرانيا": هدفت الدراسة إلى الكثف عن الإنساءة (Michael Kerfoot \& et. Al, 2009)

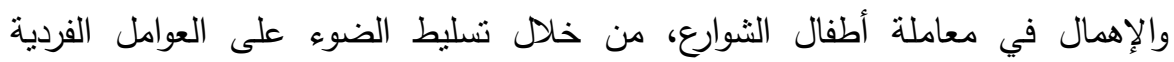

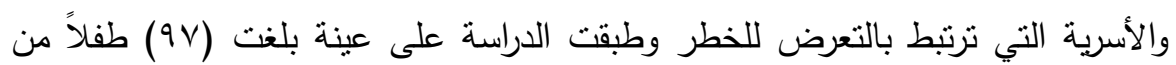

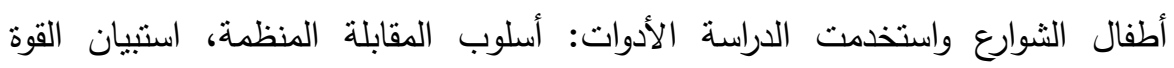
والصعوبات (SDQ)، استيان المشاعر والمزاج (MFQ)، وتوصلت إلى بعض النتائج

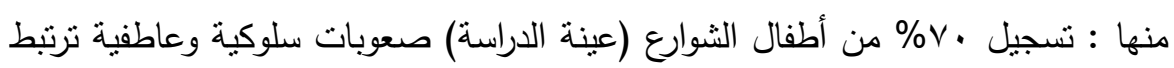

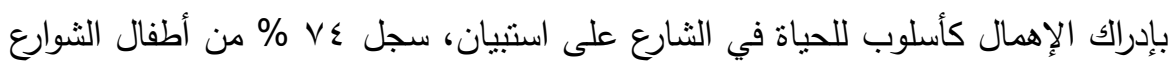

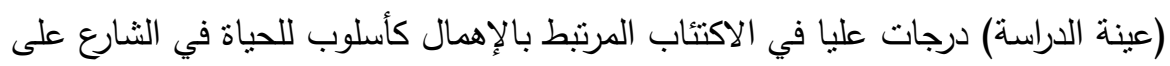

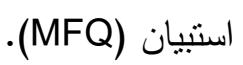
1-اختار تلث العينة الحياة في الثنارع بديلاً عن الإقامة مع الأسرة. ك-ترتبط الإقامة في الثارع بمعدلات عالية من الإساءة البدنية والعاطفية والإهمال.

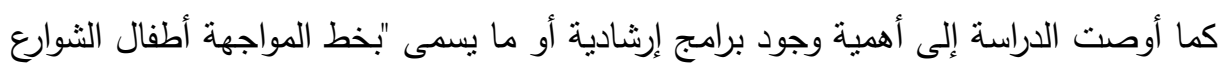

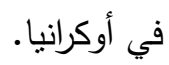

(؛) دراسة بغنوان "تصور مقترح لدور الخدمة الاجتماعية في مواجهة ظاهرة شباب

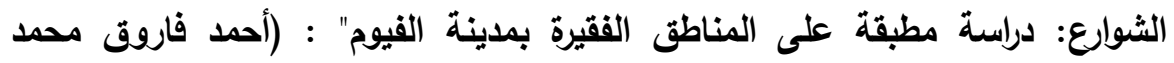

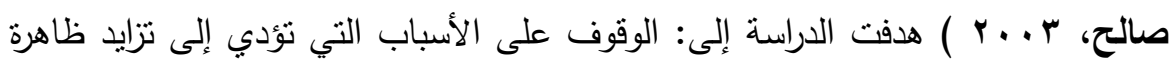

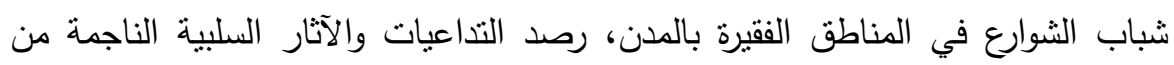


تزايد ظاهرة شباب الثوارع بالمناطق الفقيرة بالمدن، التوصل إلى تصور مقترح لدور

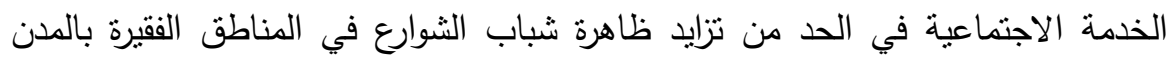

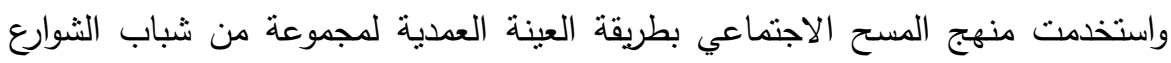

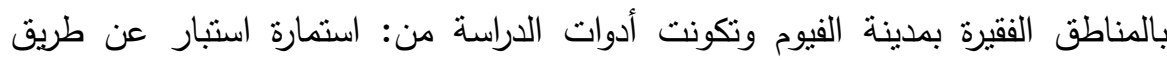

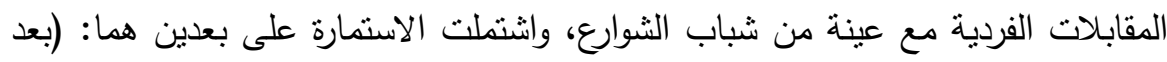
خاص بالأسباب التي تؤدي إلى تزايد الظاهرة منها ما هو مرتبط بالمناطق الفقيرة والأسرة

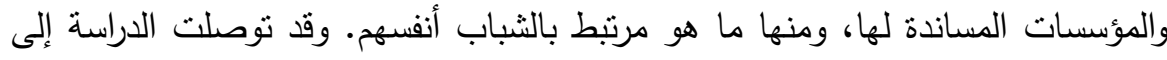

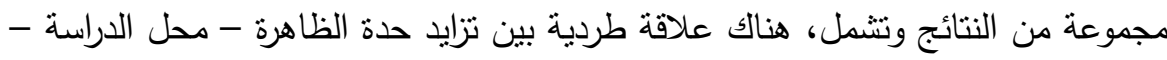
وخصوصية المناطق الفقيرة التي تميزها عن غيرها من أجزاء المجتمع الأخرى، تلك فئك

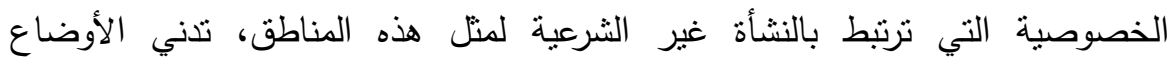
الاقتصادية والمعيشية والعمرانية وانتشار الفقر والجريمة بها، بالإضافة إلى تعدد الأنشطة

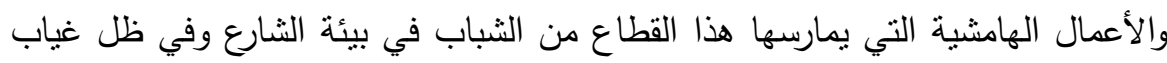

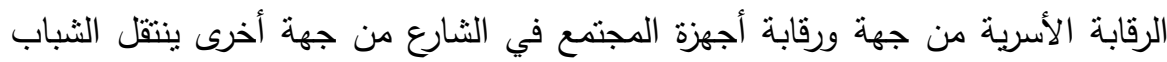

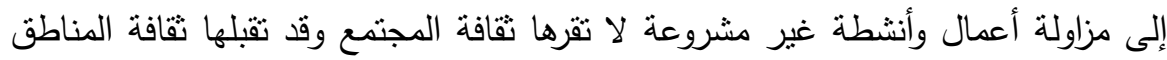
الفقيرة السائدة، تميز ظاهرة شباب المجتمع وقد تقبلها ثقافة المناطق الفقيرة، بارتباطها الطبقي القوي حيث ترنبط بنوعية معينة من الثباب الذين ينحدرون من طبقة ذات أوضاع اقتصادية واجتماعية متدنية ويتطفون بمجموعة من الصفات المشنركة، أهمها تبني ثقافة

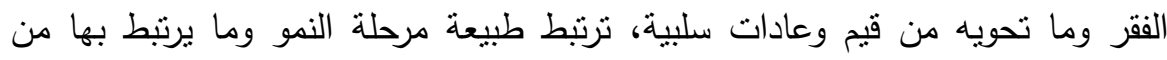

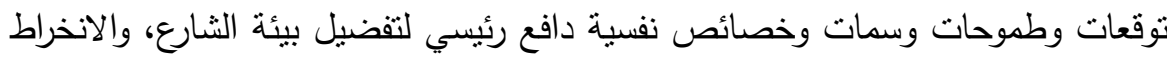
المبكر فيها، رغبته في تحقيق الاستقلالية والاعتماد على الذات، من أهم الأسباب المؤدية إلى تزايد الظاهرة يتمثل في تراجع دور الأسرة عن تلبية وإثباع الاحتياجات الأساسية،

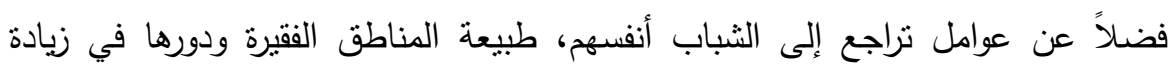




\section{منهمبية المهته}

أ- منهج البحث: استخدمت الباحثة ( المنهج شبه التجريبى ) لملاعمته لموضوع البحث، حيث يعد من أهم النماذج المستخدمه لمعرفة تأثثير المتغير المستقل على التابع، حيث التيثل استخدام التجربة كإحدى الطرق السائدة فى دراسة بعض العوامل ومعرفة نتائجها ودرجة تأثيرها على مجموعة آخرى من نفس المجتمع تتخذ كمجموعة ضابطة.

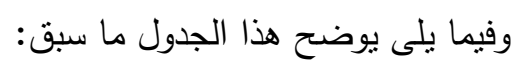

جدول رقم( (1) يوضح طريقة استخدام التجربة فى تطبيق برنامج البحث

\begin{tabular}{|c|c|c|c|}
\hline الإختبار البعدى & المعالجة & الإختبار القبلى & المجموعة \\
\hline مقياس المواقفة البئية & البرنامج المقترح & مقياس المواقفية البيئية & التجريبة \\
\hline مقياس المواقفة البئية & للبرنامج الاتتعرضز & مقياس المواقفية البيئية & الضابطة \\
\hline
\end{tabular}

حيث تم إجراء الإختبار القبلى لعدة مرات متتالية ثم إدخال (المتغير المستقل) ويليه إجراء الإختبار البعدى لعدة مرات أثناء وبعد الإنتهاء من تطبيق البرنامج ( التتبعى والبعدى ) لقياس مدى التغير الذى أحدثثه المعالجة .

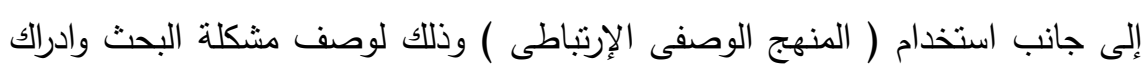

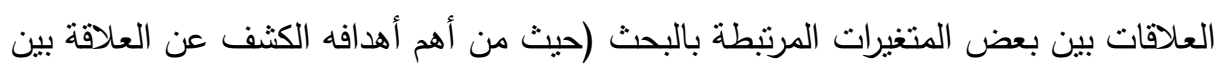

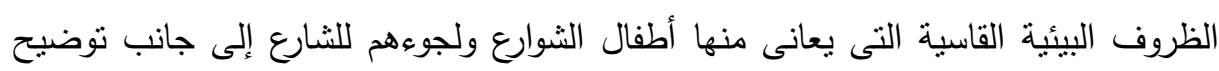
بعض العوامل المسببة فى خروجهم للثارع والنتائج المترتبة عليها منل ظروف البيئة الفيزيقية،

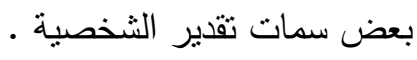
ب-عينة البحث: اختيرت عينة التطبيق (بالطريقة العشوائية )، كما نم مراعاة بعض نايز

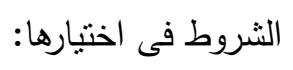

-أن يكون الطفل المشترك فى البرنامج متردداً على مركز الإستقبال بإستمرار، وذلك لضمان انتظام حضور الأطفال عند تطبيق البرنامج.

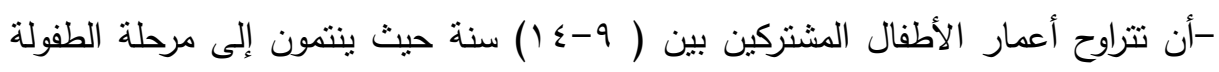
المتأخرة. 
- أن يكون الأطفال منحدرين من مناطق متدهورة بيئياً. - أن تشنمل العينة على ذكور وإناث.

وتم تقسيم العينة إلى مجموعتين: المجموعة التجريبية وتكونت عينة الدراسة من (•r) طفل شارع ومجموعة ضابطه تكونت من (•r) طفل شارع ممن يقطنون بالمناطق المتدهورة بيئياً وهذه المجموعة هى التى تم تطبيق البرنامج عليها بهدف تعديل بعض أنماط السلوك البيئى. ج- أدوات البحث: ضم البحث مجموعة من الأدوات وقد تم إعداد بعضها حتى تلاءم طبيعة الدراسة ولكى يتم التحقق من الفروض التى حددتها الدراسة، وذللك بعد التأكد من صحة ثباتها وصدقها ونتثل: 1-مقياس المواقف السلوكية البيئية ( إعداد الباحثة ) r-برنامج تعديل بعض أنماط السلوك البيئي (إعداد الباحثة )

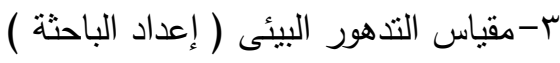
ع-مقياس تقدير الثخصية للأطفال ( إعداد ممدوحة سلامة )

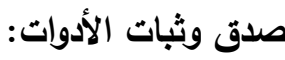

1-مقياس المواقف السلوكية البيئية: ( إعداد الباحثة ): وصف المقياس: هو أداة هدفت إلى تحديد بعض أنماط السلوك البيئى للطفل، تكون المقياس

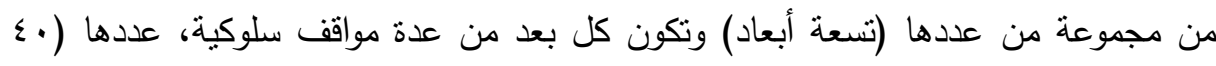

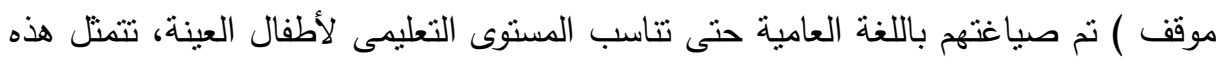

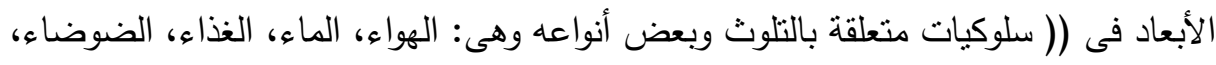

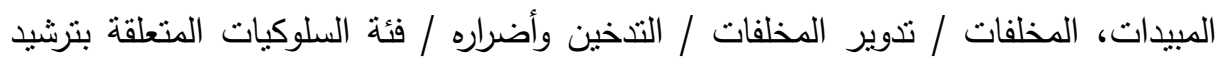

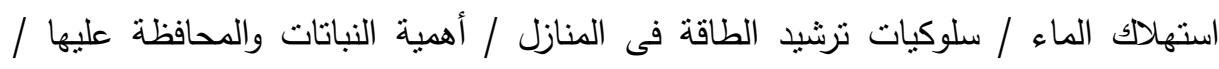

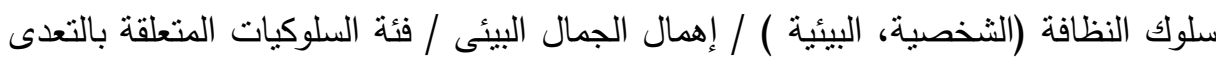
على البيئة). 
بالنسبة لحساب ثبات المقياس:( طريقة إعادة الإختبار) وقد قدم المقياس إلى (10) من

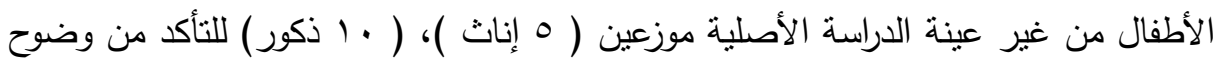

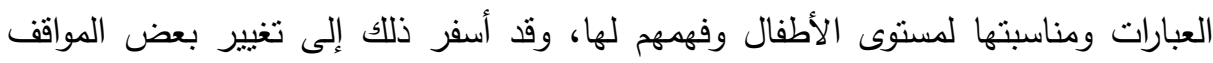

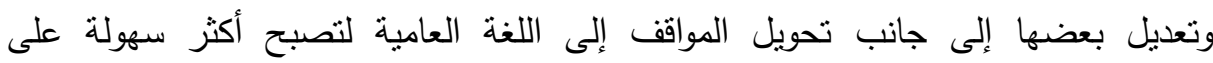

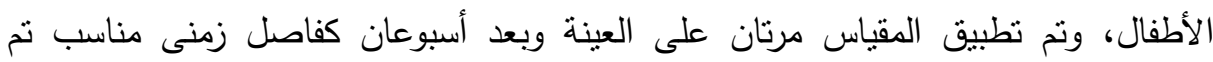

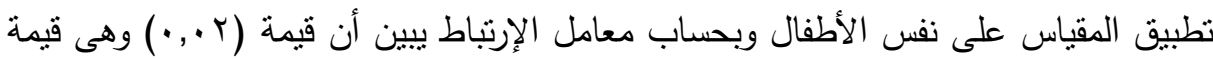
دالة إحصائياً على الثبات.

أما بالنسبة لصدق المقياس: تم استخدام طريق صدق المحكمين حيث تم عرض المقياس

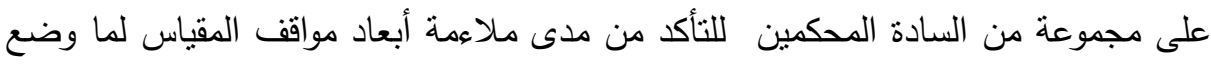
لقياسه بالنسبة لفئة أطفال الثوارع والمرحلة العمرية التى ينتمون إليها.

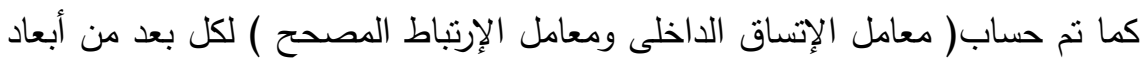

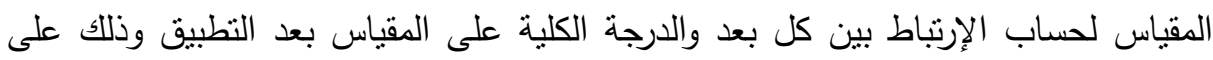

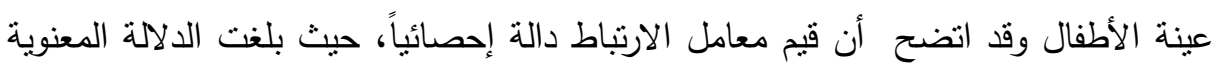

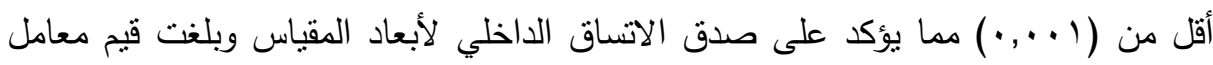

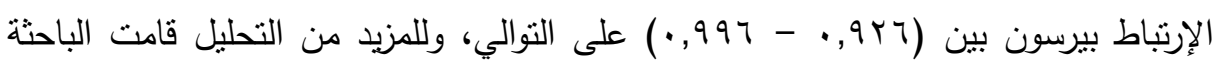

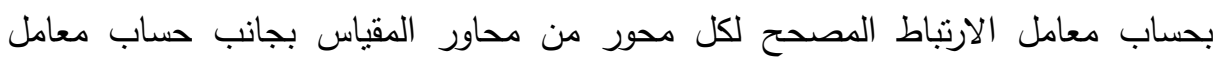

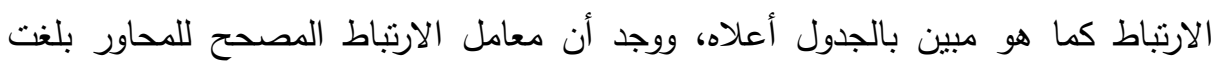

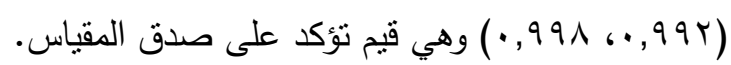

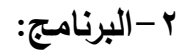

اللهاف العام من البرنامج: يتركز الهدف الرئيسي من البرنامج على تعديل بعض أنماط

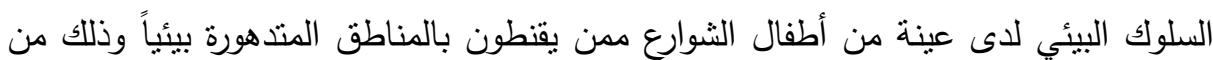

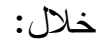


- القيام ببعض الأنشطة البيئية التى تساعدهم على اكتساب السلوكيات الإيجابية.

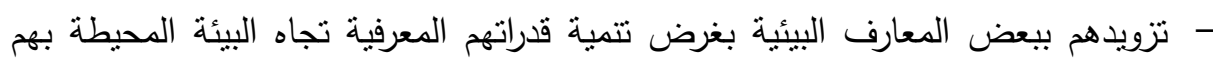

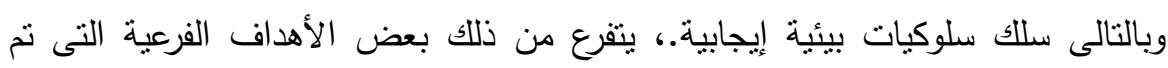

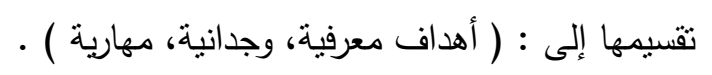

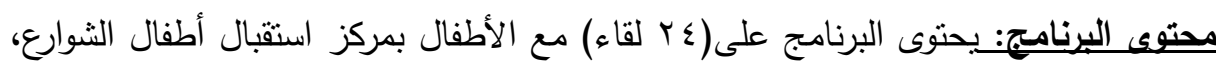

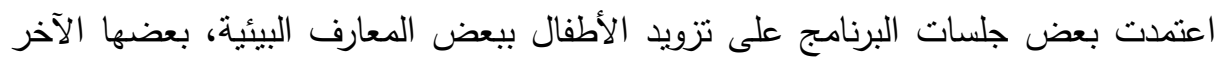

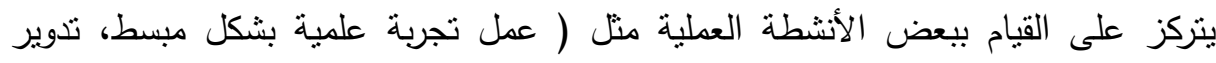

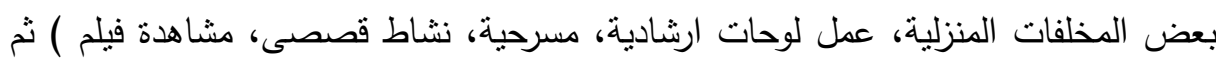

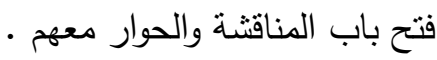
الفنبات المستخدمة في البرنامج: ركز البحث الحالى على استخدام مجموعة من الفنيات السلوكية من أجل تحقيق هدف البرنامج وتتشمل على: - أساليب معرفية: (المناقثنة الجماعية - التشجيع - الثرح والتفسير )

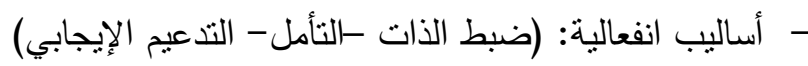
- أساليب سلوكية: (لعب الدور - النمذجة- النشاط القصصى).

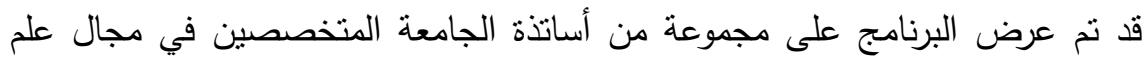
النفس والصحة النفسية ومجال البرامج ومناهج التدريس، وذللك من أجل إبداء رأيهم في

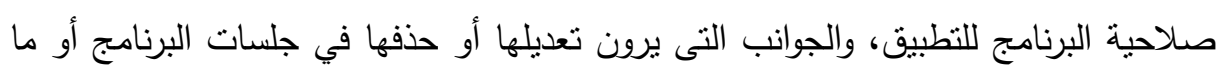

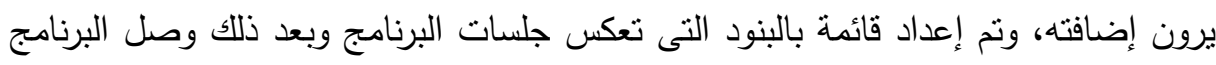

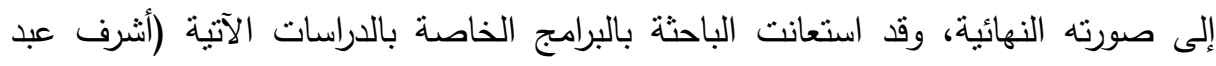

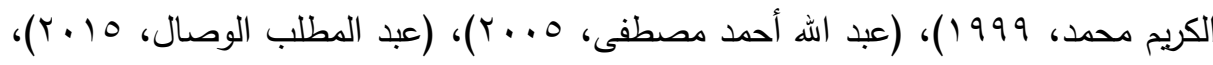

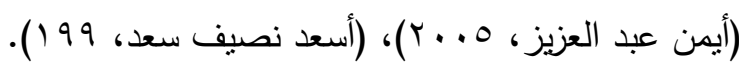
r-مقياس تقدير الثخصية للأطفال: ( إعداد ممدوحة سلامة ) أعدته للعربية ( ممدوحة

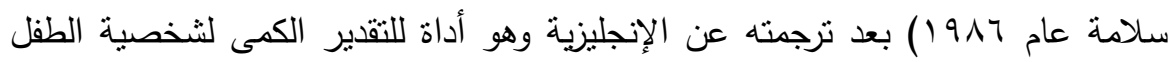

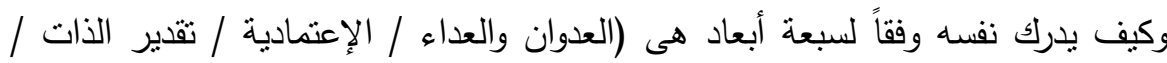


الكفاية الثخصية / التجاوب الإنفعالى / النظرة للحياة )، تحتوى الصورة الخاصة بالأطفال

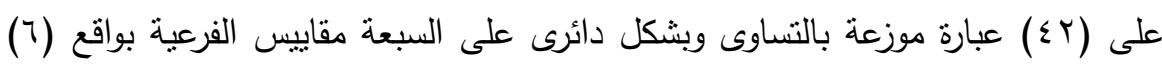
عبارات لكل مقياس.

بالنسبة لحساب ثبات المقياس: للتحقق من ثبات المقياس استخدمت الباحثة معادلة ألفا كرونباخ (Alpha Cronbach)، واتضح ان قيم معاملات الثبات لأبعاد المقياس جميعها قيم

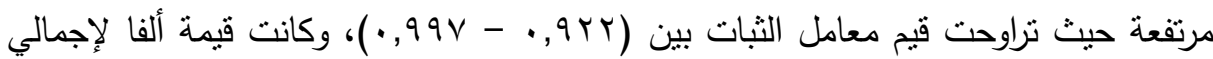
المقياس (997, •)، وتثير هذه القيم من معاملات الثبات إلى صلاحية المقياس للتطبيق

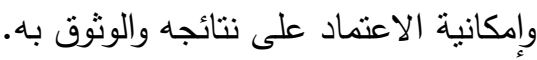
بالنسبة لحساب صدق المقياس: قامت الباحثة بحساب صدق الإتساق الداخلي ومعامل الارتباط المصحح لكل محور بإجمالي المقياس لحساب الصدق الاتساق الداخلي السابق

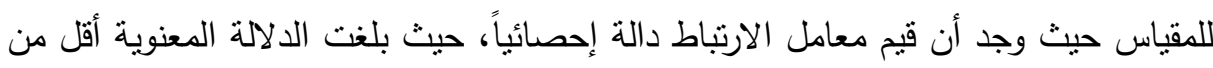
(1 (., •) مما يؤكد على صدق الاتساق الداخلي لأبعاد المقياس وبلغت قيم معامل الإرتباط

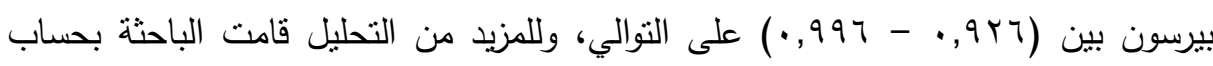

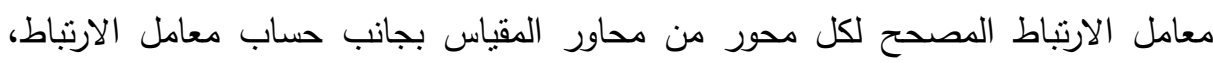

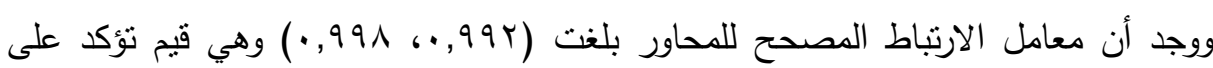
صدق المقياس. ع-مقياس التدهور البيئى: ( إعداد الباحثة ) ركز المقياس على بعض الأسئلة الخاصة

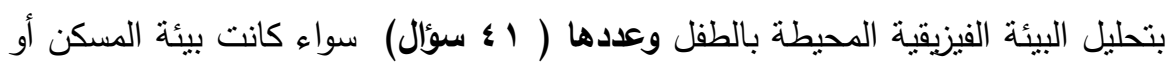

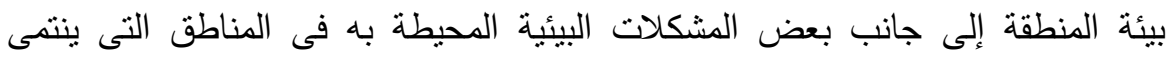

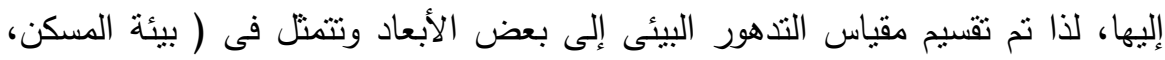

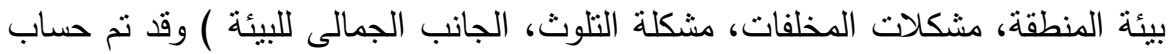
ثنات وصدق المقياس كما يتضح فيما يلى: لينه 
للتحقق من ثبات المقباس: للتحقق من ثبات المقياس استخدمت الباحثة معادلة ألفا كرونباخ Alpha Cronbach)

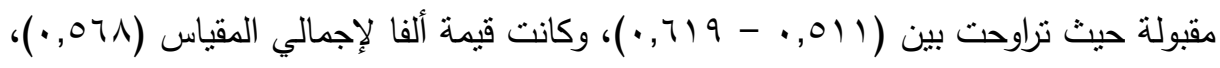

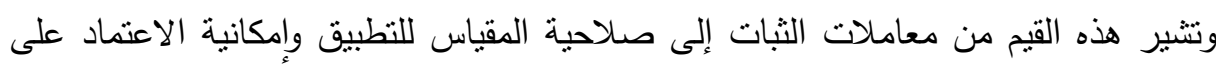

للتحقت من صدق المقباس: قامت الباحثة بحساب صدق الإتساق الداخلي ومعامل الارتباط

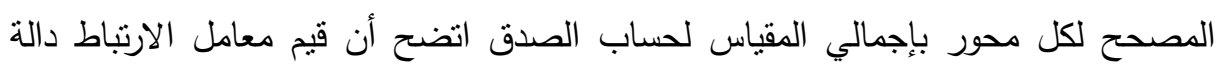

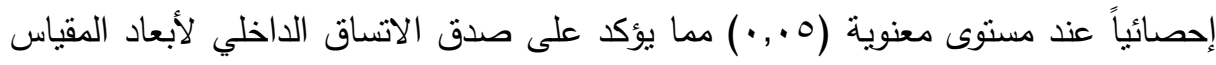

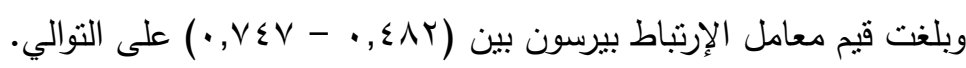

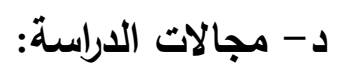

-المجال المكانى: نم إجراء الدراسة الميدانية بمركز استقبال أطفال الثوارع، التابع لجمعية

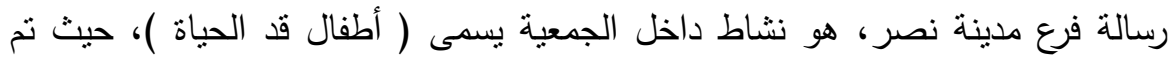
تطبيق البرنامج المقترح وأدوات الدراسة على عينة من الأطفال (الذكور والإناث) المنرددين

$$
\text { على المركز. }
$$

-المجال البشرى: نكونت عينة الدراسة من ( •r طفل ) من أطفال الثوارع النازحين من

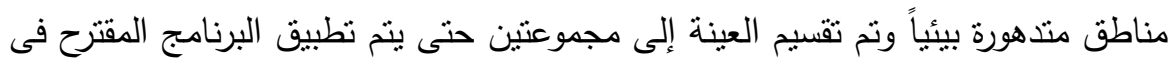

$$
\text { الدراسة الراهنة. }
$$

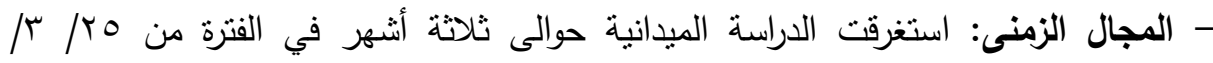

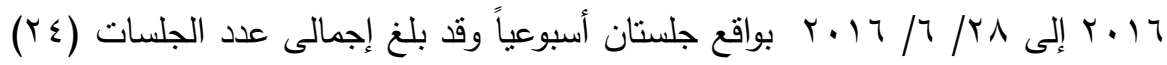

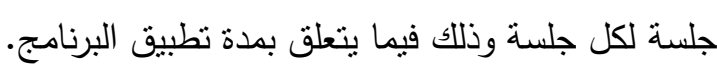

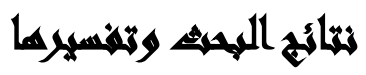

(1) الفرض الأول: الذى ينص على (توجد فروق ذات دلالة احصائية بين متوسط درجات أطفال المجموعة التجريبية على أبعاد مقياس المواقف السلوكية البيئية فى القياسين (القبلى 
والبعدى) لصالح القياس البعدى )، والجدول التالى يوضح نتائج المعالجة الإحصائية، وفقاً

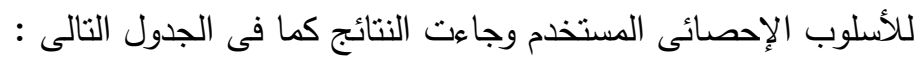
جدول رقم(ץ): اختبار ت T-Test لحساب الفروق بين متوسط درجات أطفال المجموعة التجريبية على أبعاد مقياس المواقف السلوكية البيئية فى القياسين (القبلى

\begin{tabular}{|c|c|c|c|c|c|c|c|}
\hline \multirow{2}{*}{ التأثجر } & \multirow{2}{*}{ معنّوي } & \multirow{2}{*}{ قتيمة } & \multicolumn{2}{|c|}{ التطبيق البُعدي } & \multicolumn{2}{|c|}{ التطبيق القبلى (r) } & \multirow{2}{*}{ الموأقفاد مقياسية السلوكية } \\
\hline & & & المعياري & المتوسط & الانحرافي & المتوسط & \\
\hline$\cdot, 91$ & دالة & $18, .9$ & $Y, Y T$ & $19,1 \vee$ & $T, V T$ & $\Lambda, \cdot r$ & النلوث بأنواعه \\
\hline$\cdot, \wedge \mathrm{T}$ & دالة & IY,AYq & $\cdot, 9 \leq$ & $\varepsilon, \wedge \vee$ & $\cdot, 99$ & $1,7 V$ & تدوير المخلفات \\
\hline$\cdot, \vee \wedge$ & دالة & $9, \varepsilon \cdot q$ & •, & $\varepsilon, 7$. & 1, & $r, \cdot V$ & ترشيد استهلاك \\
\hline$\cdot, 79$ & دالة & $V, r \cdot V$ & $\cdot, V Y$ & $r, r v$ & $1, \cdot r$ & $1, V$. & ترشيدة استهالالكنازل \\
\hline$\cdot, \Lambda Y$ & دالة & $1 \cdot, V \leqslant r$ & $\cdot, 97$ & $\varepsilon, 7 \pi$ & $1, .0$ & l,Ar & والهمبة النباتاتة عليها \\
\hline 0.60 & دالة & $\vee, 1 \wedge 4$ & $1, r 4$ & 7,11 & 1,00 & $r, \varepsilon r$ & (الشخصية،البيئة) \\
\hline$\cdot, 7$ & دالة & $0,74 r$ & $\cdot, V \varepsilon$ & $r$, & $1,1 \pi$ & 1,7 . & مواجهال إلبئيال \\
\hline$\cdot, V T$ & دالة ل & 1,970 & $1, Y \varepsilon$ & $\varepsilon, \pi$ & $\cdot, 9 Y$ & $1,1$. & أضرار التنخين \\
\hline$\cdot, \wedge T$ & دالة ل & $1 Y, 997$ & $r, \wedge \wedge$ & $I Y, I V$ & $1, \leqslant 1$ & $\varepsilon, O V$ & التعدي على البيئة \\
\hline$\cdot, 90$ & دالة & Tr, 9Y & $\vee, \cdot$ & TY,YV & $\varepsilon, V T$ & $r \uparrow, V$. & المواقفالى السلوكية \\
\hline
\end{tabular}

يتضح من الجدول السابق وجود فروق بين القياسين (القبلى والبعدى) المجموعة التجريبية على أبعاد مقياس المواقف السلوكية البيئية وذلك لصالح القياس البعدى، حيث لهين

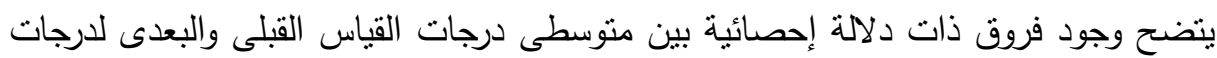

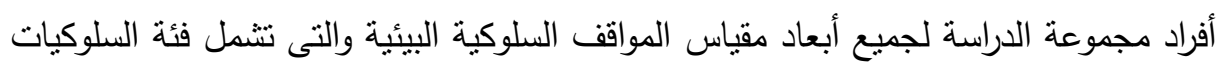

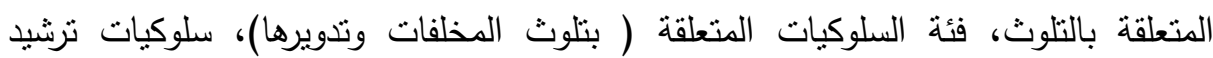
استهلاك المياه، سلوكيات ترشيد استهلاك الطاقة بالمنازل، سلوكيات أهمية النباتات والمحافظة

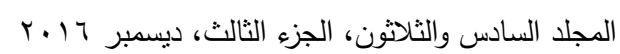


عليها، سلوكيات (النظافة الثخصية، نظافة البيئة)، سلوكيات مواجهة إهمال الجمال البيئي،

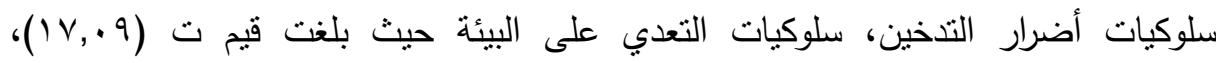

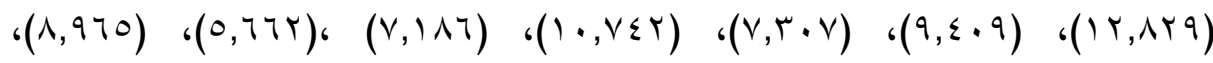

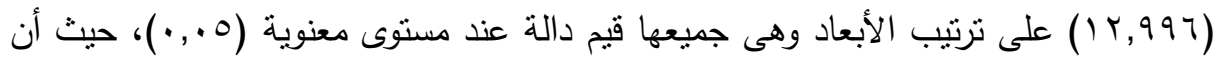
الدرجة العالية تعبر عن مستوى أعلى من السلوك البيئى الإيجابى، كما كان حجم التأثير مرتفع على جميع أبعاد المقياس، وهذا يعنى تحقق الفرض الأول إحصائياً.

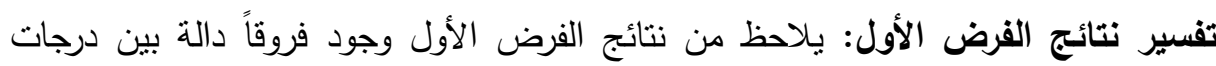

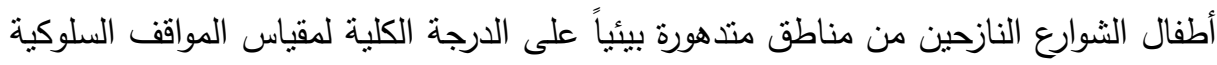
البيئية وجميع أبعاده، لصالح التطبيق البعدى لبرنامج تعديل السلوك، وترجع الباحثة تلك الكئ

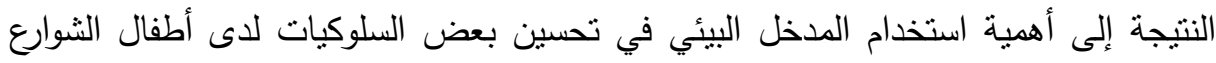

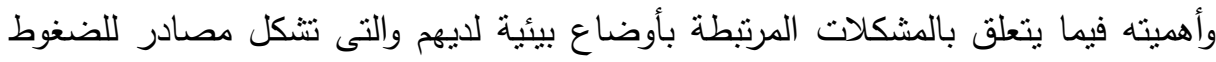

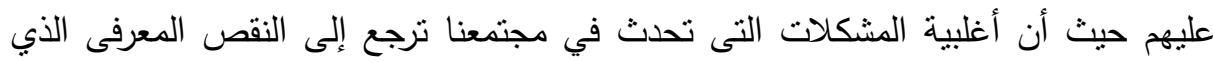
يحرم منه الطفل خاصة والفرد عامة وحدة بالمعلومات الصحيحة حيث يبدأ في سلك سلوكيات إيجابية، وفي المقابل تفتقد الكثثر من الأسر في مجتمعاتتا الحالية وخاصة لدى الأطفال الذين بالئ

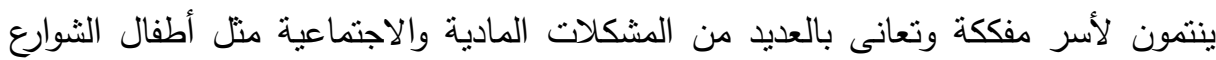
حيث نجد أن هذه الأسر نسعى فقط إلى كسب الرزق لأبناءهم أو عدم تلبية أبناءهم لنصائحهم

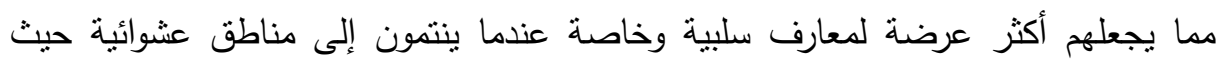
المسكن غير المناسب ونقص الدخل والإصابة بالأمراض وسوء الأخلاق وتدنى مستوى التعليم وغيرها، لذلك فإن الاهتمام بالجانب المعرفى لديهم وتوعيتهم بالعديد من المفاهيم الخاصة بالمشكلات والسلوكيات البيئية يرتبط بالنجاح في سلك سلوكيات بيئية إيجابية نحو بيئتهر

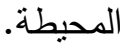
وتتفق هذه النتيجة مع نتائج بعض الدراسات منها دراسة (أسماعيل مصطفى سالم، (Y...

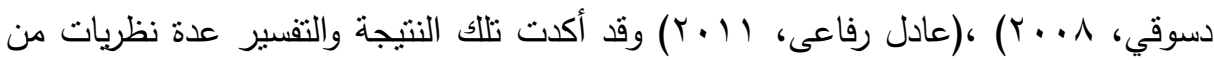


أهمها (نظرية التعلم الاجتماعى) حيث تعتبر هذه النظرية أمتداد للتعلم بالتقليد والنمذجة، حيث تتترك هذه النظريات في التركيز على أهمية التفاعل الاجتماعى إذ يعمل المجتمع مؤسساته على تعزيز أو عقاب السلوك الصادر من الفرد، كذلك تأكيد أصحاب (نظرية بياجية المعرفية) على أهمية البيئة المناسبة للمرحلة التى يمر بها الفرد المتعلم، حيث يتميز النمو بوجود مراحل

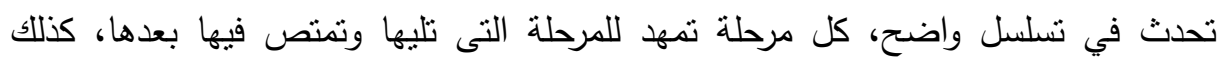
نموذج (التعلم المعرفى) الذي يركز على إدراك الفرد للمواقف التى يسلك خلالها سلوكياته

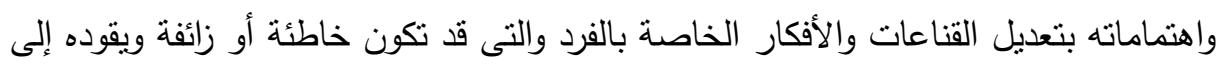
القيام ببعض السلوكيات التى لابد من تغييرها حتى ينظر إلى الأمور نظرة مختلفة، وتتفق ذلك

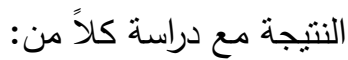

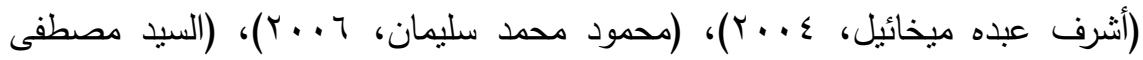

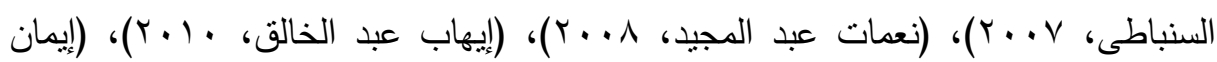

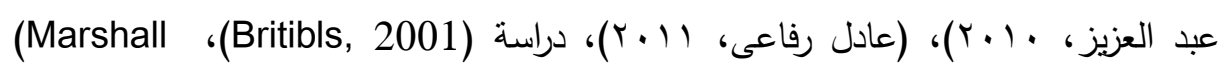

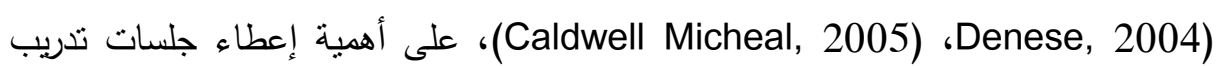
معرفى للأطفال والتى أثنتت بعض منها وجود علاقة إيجابية بين البرنامج وتتمية الثقافة البيئية

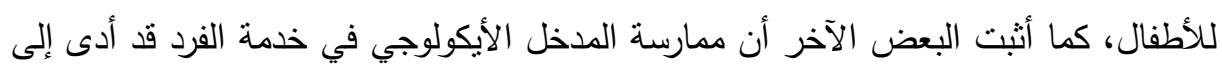

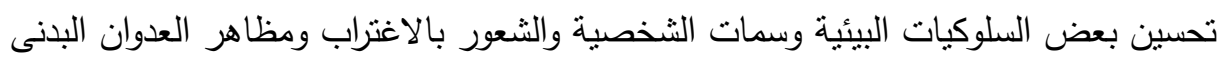
واللفظى والتخريبي وتتمية بعض القيم وتتمية الوعى المعرفى لديهم. (r) نص الفرض الثانى: " توجد فروق ذات دلالة احصائية بين متوسطي درجات

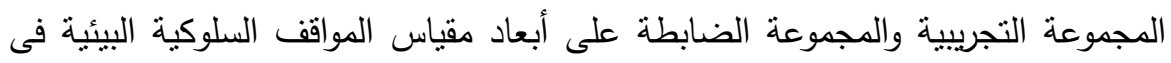
القياس البعدى لصالح المجموعة التجريبية" 
جدول رقم(ץ): اختبار ت T-Test لحساب الفروق بين متوسطى درجات المجموعة التجريبية

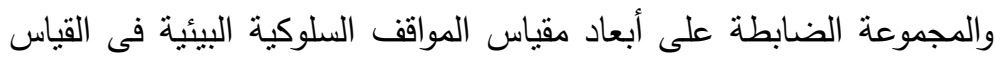

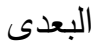

\begin{tabular}{|c|c|c|c|c|c|c|}
\hline \multirow{2}{*}{ معنتو معنوية } & \multirow{2}{*}{ قيمة (ت) } & \multicolumn{2}{|c|}{ 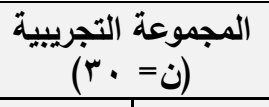 } & \multicolumn{2}{|c|}{ 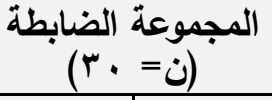 } & \multirow{2}{*}{ المتغيرات } \\
\hline & & المعياري & المتوسط & الالانحراف & المتوسط & \\
\hline دالة & $I V, \Sigma 7 Y$ & Y,YT & $19,1 \mathrm{~V}$ & T,V. & $V, q \mu$ & التلوث بأنواعه \\
\hline دالة & $1 r, r q 1$ & $\cdot, 9 \leq$ & $\varepsilon, \wedge V$ & $\cdot, 10$ & $1, \wedge$. & النلوث بالمخلفات وتدويرها \\
\hline دالة & $9,7 Y \wedge$ & $\cdot, \wedge 7$ & $\varepsilon, 7$. & $1, \cdot \varepsilon$ & $T, Y M$ & ترشيد استهلالك المياه \\
\hline دالة & $V, 0 \leqslant$. & $\cdot, V Y$ & $r, \mu \nu$ & $\cdot, \lambda Y$ & l, ^V & تالثنازل استهلآك الطاقة \\
\hline دالة & $1 \cdot, 910$ & $\cdot, 97$ & $\varepsilon, \pi$ & • & $1,9 \vee$ & آهيهية النباتات والمحافظة \\
\hline دالة & $\Lambda, 1 Y \uparrow$ & צ'ו & $7,1 \pi$ & $1, \Gamma \varepsilon$ & r, & البيئية النية الثخصية والنظافة \\
\hline دالة & $0,\{71$ & $\cdot, \vee \vee \leqslant$ & r, & $\cdot, \wedge 4$ & $1, \wedge \mathrm{V}$ & البيئجية إهمال الجمال \\
\hline دالة & $\Lambda, \vee 01$ & $1, Y \varepsilon$ & $\varepsilon, r M$ & $\cdot, \wedge 1$ & $1,9 V$ & أضرار التنخين \\
\hline 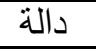 & Ir,TV. & $r, \wedge \wedge$ & $I Y, I V$ & $1, \cdot V$ & $\varepsilon, 0$ & التعدى على البيئة \\
\hline دالة & $r r, q .0$ & $9,1 \leqslant$ & $\wedge \neg, 1 \Gamma$ & 0,70 & $r q, r \mu$ & ألسلوكية مقياس المواقف \\
\hline
\end{tabular}

يتضح من الجدول السابق أنه توجد فروق بين متوسطى درجات المجموعة التجريبية

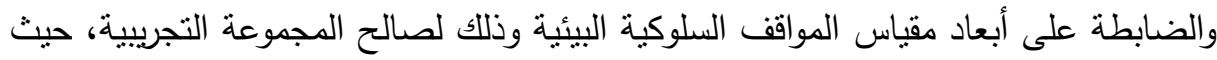
يتضح وجود فروق ذات دلالة إحصائية بين منوسطى درجات الأطفال على جميع أبعاد البهاد مقياس المواقف السلوكية البيئية فى الهجموعتين (التجريبية والضابطة) لصالح المجموعة التجريبية، وكانت دالة عند جميع المستويات (0.,.) وهذا يعنى تحقق الفرض الثانى إحصائياً. 
تفسير نتائج الفرض الثانى: تنفق هذه النتيجة مع بعض الدراسات التى تركز أهدافها على

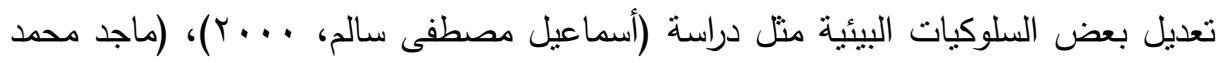

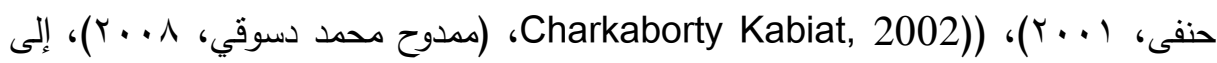
جانب الدراسات التى هدفت إلى استخدام المدخل المعرفى السلوكى مثل دراسة (حنان محمد

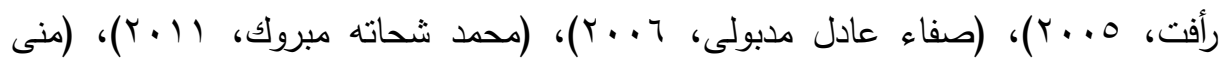

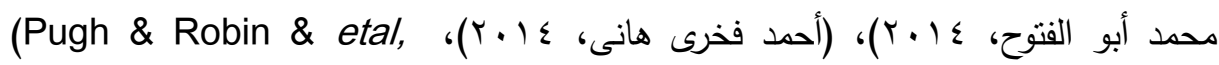
(Williams \& etal, 2004) (Laroon \& etal, 2004) ،يث أظهرت جدوى (2004) أنشطة البرنامج المعرفى السلوكى في تتمية بعض السلوكيات للطفل وتعديل بعض الأنماط

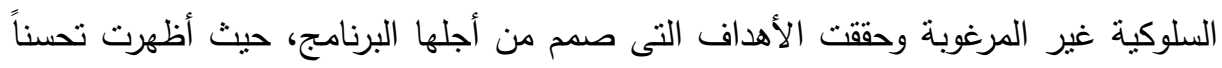

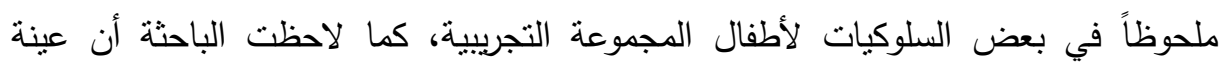

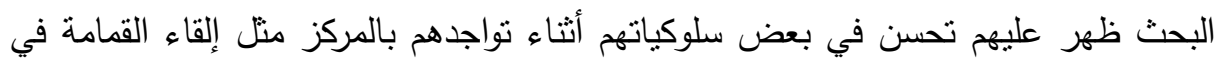
سلات صنعها الأطفال بأيديهم من خلال نثاط (تدوير المخلفات) الذي تم فيه إعادة استخدام بعض الجرادل وتزينها واستخدامها في إلقاء القمامة، إلى جانب رغبة الأطفال في رؤية ماذا

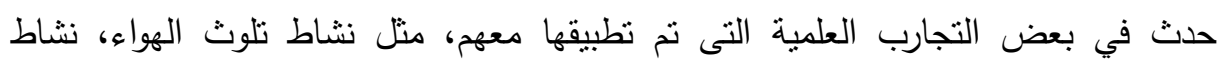

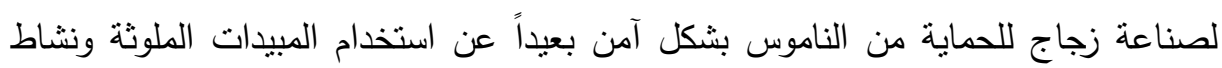

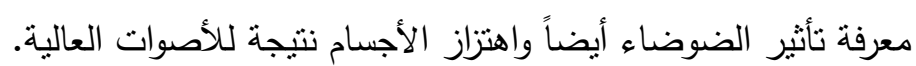

ومن بعض الأساليب التى قد تكون سبب في تحقيق هدف البرنامج استخدام (استراتيجية

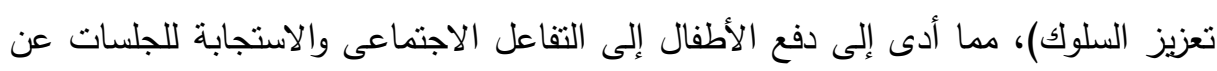

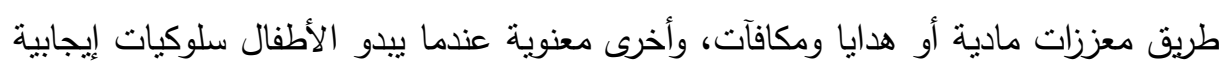

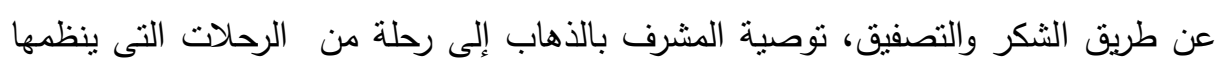

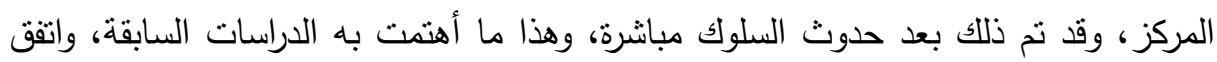

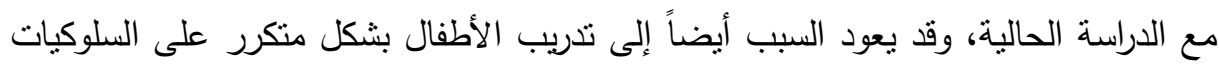

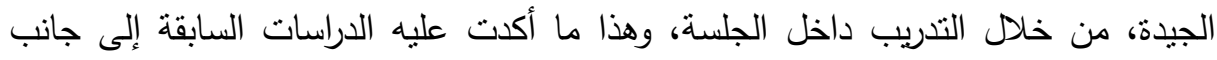
استخدام لغة حوار جيدة مع الأطفال وحتهم على التفكير في طرق إبداعية لحل المشكلات. 
وقد اتفقت عدة دراسات مع هذه النتيجة، من حيث وجود فروق دالة في التطبيق البعدى

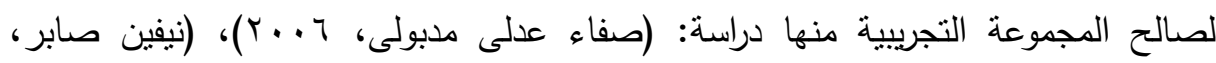

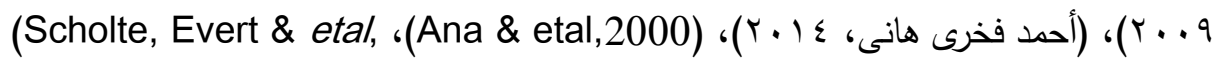

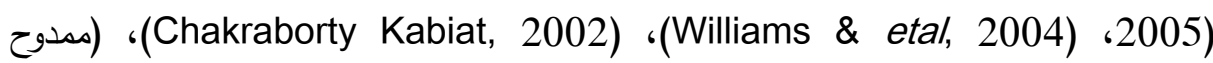

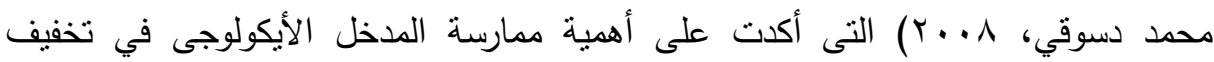
الثعور ببعض المشكلات النفسية لدى أطفال الثوارع مثل (الثعور بالعزلة الاجتماعية، الاغتراب، فقدان المعنى، الشعور بالرفض). (r) نص الفرض الثالث: توجد علاقة ارتباطية بين بعض سمات الثخصية (العدوان/العداء، الاعتمادية، الثقدير السلبى للذات، عدم الكفاية الثخصية، عدم التجاوب

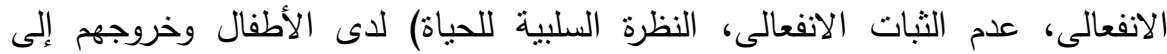

جدول(؛ ): يوضح العلاقة الارتباطية بين مقياس تقدير الشخصية وخروج الأطفال إلى الثارع

\begin{tabular}{|c|c|c|}
\hline \multicolumn{2}{|c|}{ خروج الأطفال إلى الشارع } & المتغيرات \\
\hline مستوى الدلالة & معامل الارتباط & أبعاد المقياس \\
\hline ( +, • دالة & ***,,$\Gamma 4 \leq$ & العدوان/العداء \\
\hline V V • غير دالة & $\cdot, \cdot 7$ & الإعتمادية \\
\hline ( •, • دالة & $* *, 011$ & التقديرالسلبي للذات \\
\hline ا • , • دالة & "**, & عدم الكفاية الثخصية \\
\hline 人, • غير دالة & $\cdot, \cdot T V-$ & عدم التجاوب الإنفعالى \\
\hline 7, 7 • غير دالة & $\cdot, \cdot T Y-$ & عدم التبات الإنفعالى \\
\hline r • , • دالة & ${ }^{* *} \cdot, Y \leqslant r$ & النظرة السلبية للحياة \\
\hline ا •, • دالة & "**, & إجمالى مقياس تقديرالشخصية للأطفال \\
\hline
\end{tabular}

من الجدول السابق ينبين وجود علاقة ارتباطية ذات دلالة احصائية بين خروج الأطفال

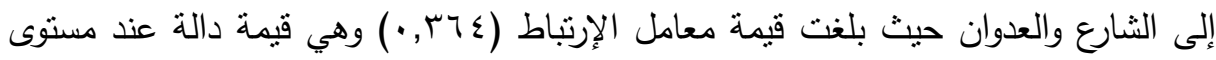
معنوية (1 +, •)، فى حين لا توجد علاقة ارتباطية ذات دلالة احصائية بين خروج الأطفال

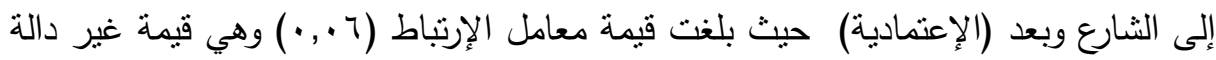


عند مستوى معنوية (V,·)، بينما وجدت علاقة ارتباطية ذات دلالة احصائية بين التقدير

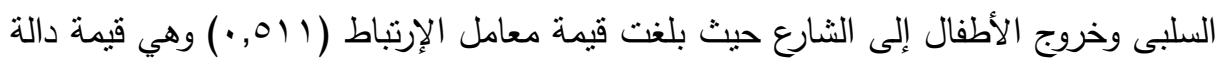
عند مستوى معنوية (1 (•,•). كما يوجد علاقة ارتباطية ذات دلالة احصائية بين نزوح الأطفال إلى الثارع وبعد عدم

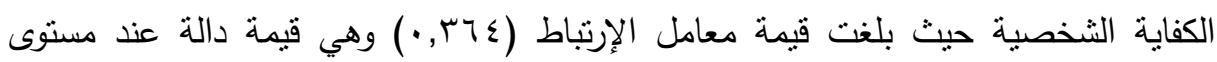
معنوبة (1 •, •).

فى حين لا توجد علاقة ارتباطية ذات دلالة احصائية بين خروج الأطفال إلى الثارع

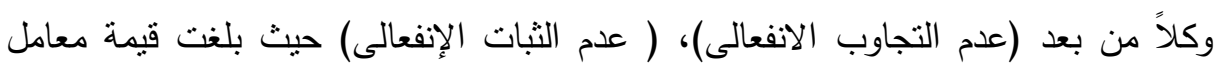

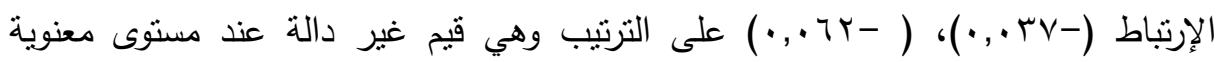

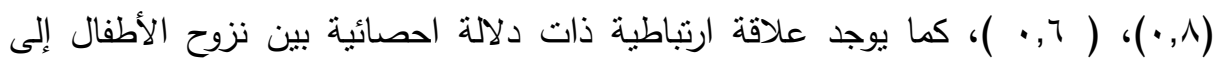

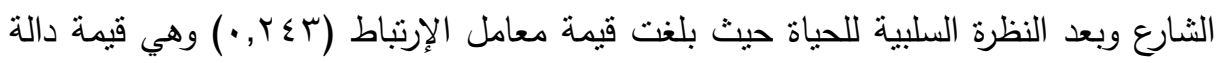
عند مستوى معنوية (r •, ·)). تفسير نتائج الفرض الثالث: يتضح من النتيجة السابقة وجود علاقة قوية بين خصائص الثخصية للأطفال وبين تشردهم من ظهور بعض المشكلات السلوكية لديهم فأرتفاع درجة

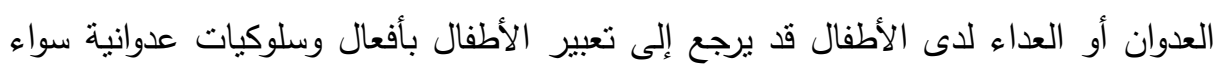

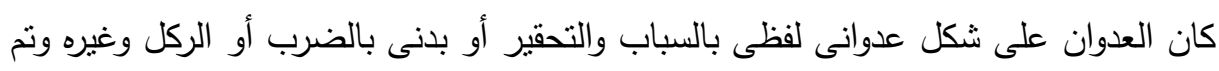

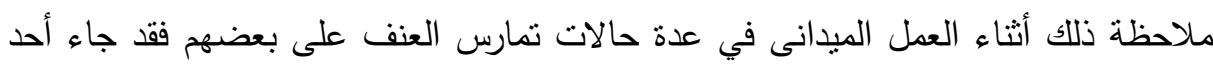

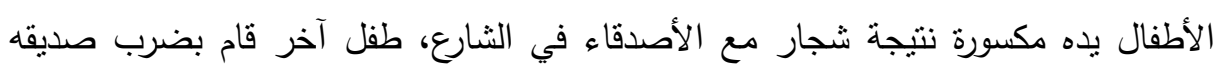

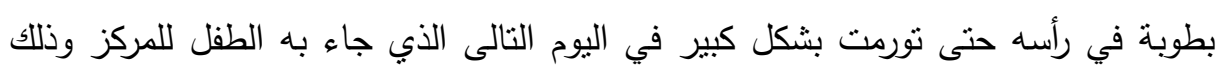

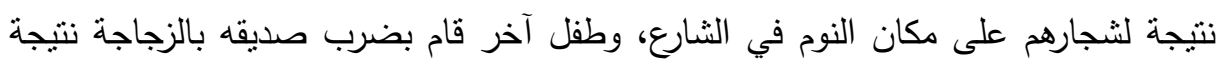

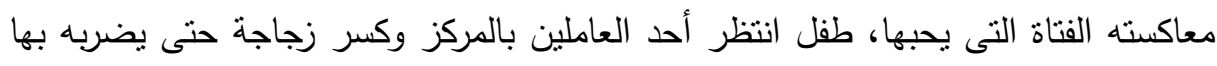
لولا معرفة أحد الأطفال لذلك وتحذيره فكل هذه السلوكيات تدل على ممارسة هؤلاء الأطفال

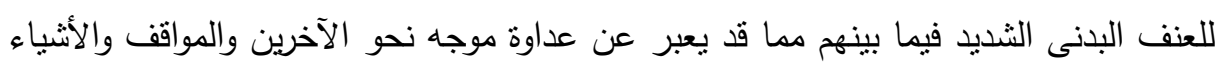
بالإضافة إلى عدوان موجه نحو الذات. 
ويلى ذلك ارتفاع درجة الأطفال على بعد (الكفاية الثخصية) الذي يعبر عن مدى تقييم الطفل لكفاءته وكفايته للقيام بالمهام العادية وقدرته على معالجة المشكلات اليومية والوفاء

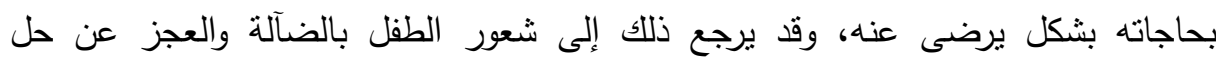

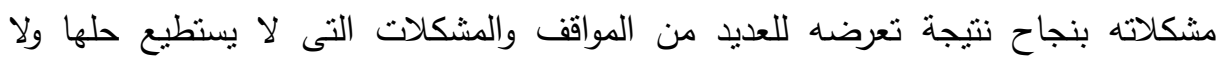
يستطيع التتافس بنجاح من أجل ما يريد الحصول عليه من مال أو عمل أو إثباع حاجاته أو لونئ فيما يهمة من مهام لذللك. وقد ارتفعت درجة الأطفال على بعد (النظرة السلبية للحياة) الذي يعنى نظرة الطفل للعالم من حوله والحياة وعلى أنه مكان طيب آمن غير مهدر أو منذر أو كما كان ملئ بالأخطار

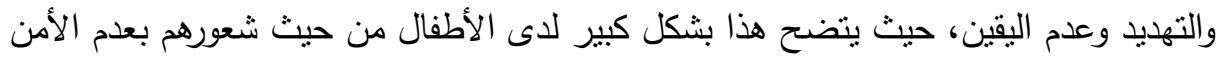

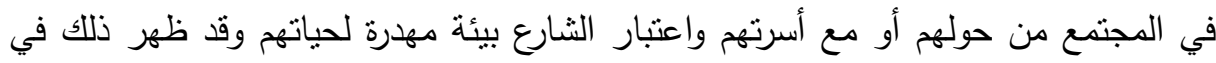

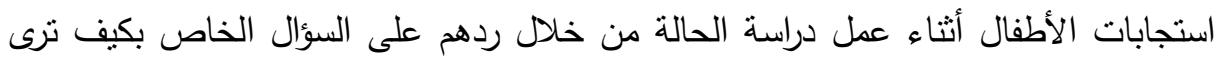

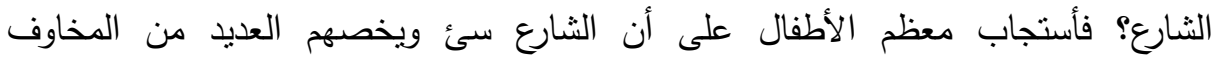
والمخاطر والتهديد والخوف من القبض عليهج والخوف أثناء النوم في الثنارع لدرجة أن بعضهم يسهر طوال الليل خوفاً من النوم بالثارع، فيعبر ذلك عن شعورهم بالتهديد والخوف من البيئة

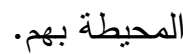

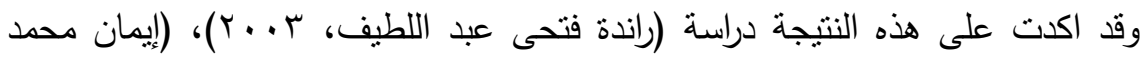

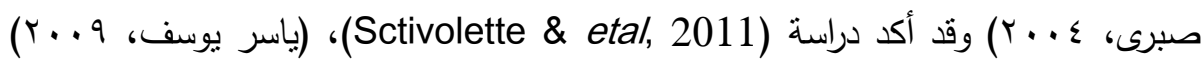
(Mayer \& etal, 2004) ، (Rouff Lisa, 2001) ،(Divoy \& etal, 2001) (Stewart \& etal, (Aksoy \& etal, 2006) (Anooshion - Linda, 2005) (Micheal Kerfoot \& etal, 2009) 2010) لموضوع الدراسة الحالية مثل (نظرية ثقافة الفقر) التى أكدت على أن من أهم السمات

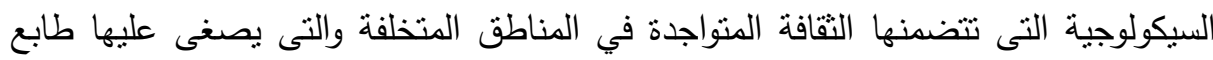
الهامشية على الثعور بالإنطواء، تحمل الأمراض النفسية ومشاق إجهاد الأعمال، الثعور والإحساس بالطبقية وتمايز المراكز، غياب الوعى الطبقى، اختصار الاحساس بالسعادة 
النفسية الناتجة عن فثله في إكتساب المهارات اللززمة، كذلك (نظرية الحاجات) التى أكدت على أن عدم إثباع حاجات الفرد يؤدي إلى الثعور بالتوتر ويؤثر على سلوكه وبقاءه والثعور

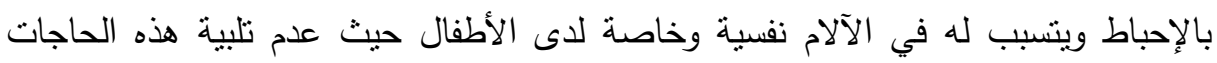

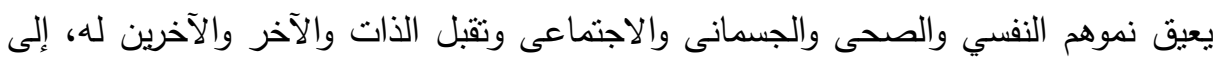

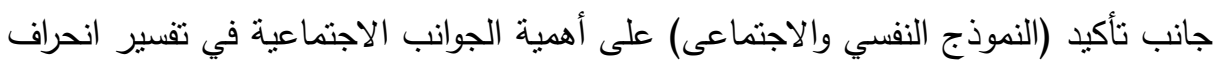

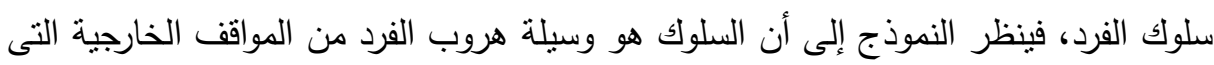
لا تحتمل، أن هناك علاقة وثيقة بين عدم الثعور بالأمن وبعض مظاهر السلوكيات لدى طفل هروب لهن

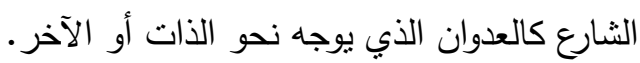
(ع) نص الفرض الرابع: توجد علاقة ارتباطية بين البيئة المحرومة القاسية التى تضم الأطفال ( التذهور البيئى ) وبعض سمات الثخصية (العدوان/العداء، الاعتمادية، التقدير

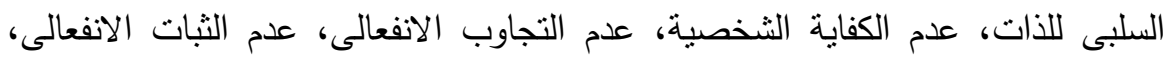

النظرة السلبية للحياة).

جدول رقم(ه): يوضح العلاقة الارتباطية بين مقياس التدهور البيئى ومقياس تقدير الشخصية

\begin{tabular}{|c|c|c|}
\hline \multicolumn{2}{|c|}{ الدرجة الكلية لمقياس التدهور البيئي } & \multirow{2}{*}{ أبعاد مقياس تقدير الثشصية } \\
\hline مستوى الدلالة & معامل الارتباط & \\
\hline r • , • • دالة & $*, r \leq 1-$ & العدوان/العداء \\
\hline 9, · غير دالة & $\cdot, \cdot Y_{1}$ & إإعتمادية \\
\hline 9, · غير دالة & $\cdot, \cdot r \leq$ & التقديرالسلبي للذات \\
\hline 0. • • د دالة & $*, Y, Y \vee 7-$ & عدم الكفاية الشخصية \\
\hline 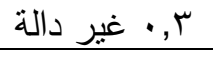 & $\cdot, 1 \leq \cdot$ & عدم التجاوب الإنفعالي \\
\hline r r • غير دالة & $\cdot, r \ldots-$ & عدم الثبات الإنفعالي \\
\hline 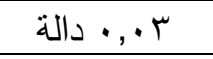 & $*, Y 19$ & النظرة السلبية للحياة \\
\hline 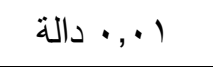 & $* *, r \leqslant \Lambda$ & إجمالي مقياس تقديرالثخصية للأطفال \\
\hline
\end{tabular}

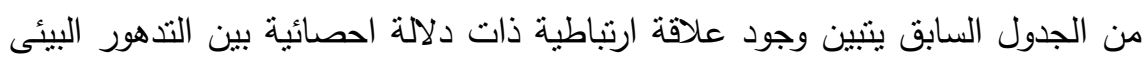



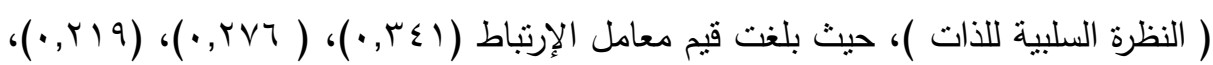


وهي قيمة دالة عند مستوى معنوية (ץ •,•))، ( •.,.•)، ( r.,.•) على الترتيب، فى حين لا توجد علاقة ارتباطية ذات دلالة احصائية على الأبعاد ( الإعتمادية )، (التقدير السلبى للذات) ( عدم التجاوب الإنفعالى)، (عدم الثبات الإنفعالى )، حيث بلغت الإعالد قيم معامل الارتباط

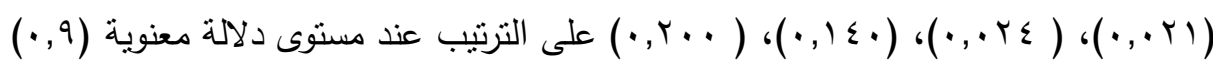

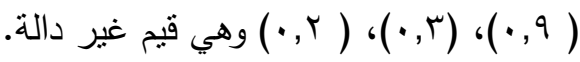
تفسير نتائج الفرض الرابع: اتضح من خلال نتيجة هذا الفرض وجود علاقة ارتباطية بين البيئة المحرومة القاسية التى يعيش وسطها الأطفال وبين ظهور بعض التهاتئ السمات الثخصية والسلوكية عليهم، وقد ظهر ذللك في بعض السلوكيات دون غيرها مثل (العدوان - عدم الكفاية

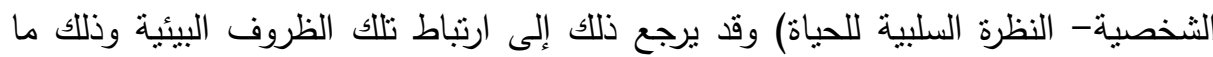
يؤكده التراث النظرى أن الأطفال المقيمين بالمناطق المتدهورة يتأثرون بالانحراف والجريمة التى تحيط بهم، بل أن الطفل أيضاً داخل أسرته ينترب المواقف بأن غير السوية ونماذج السلوك المنحرفة من أفراد أسرته المنحرفين المحيطين به في بيئته إلى جانب المشاجرات التى تحدث من حولهم من سنج ومطاوى وهو ما يمنل عرضاً يومياً مفتوحاً للصغار والصبية للتعليم

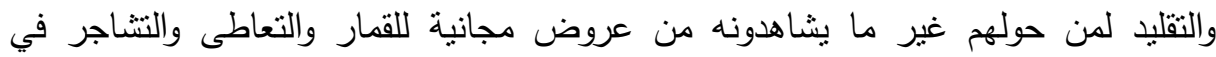
الثوارع ومن النوافذ وما يسمعونه من شتائم وغيره، وذللك ما يعبر عنه الطفل من خلال تشربه من البيئة المحيطة به وسلكه سلوكيات عدوانية، إلى جانب الزحام في الغرف والمنطقة وغيره

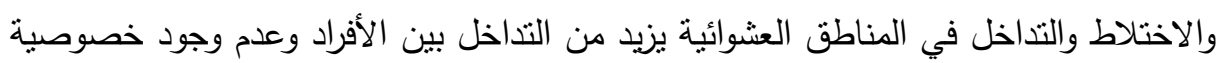

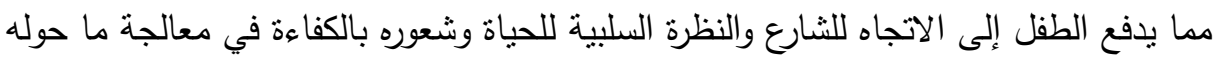
وأن يجد حل للمشكلات البيئة المحيطة به.

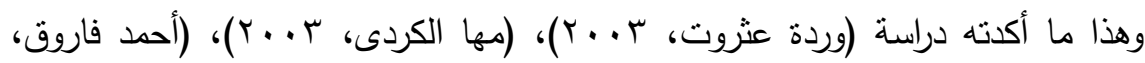

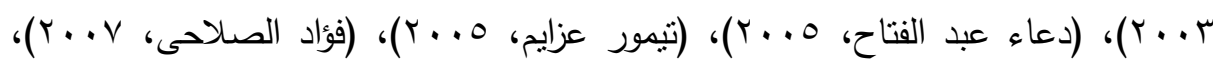

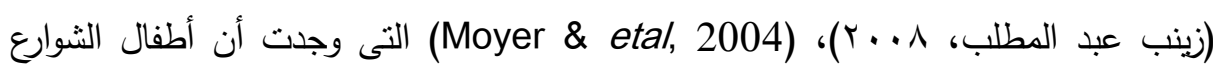
سجلوا أقل درجات على اختبار الثبات الانفعالى، تقدير الذات السلبي. 
وقد أكدت على ذلك (نظرية ثقافة الفقر) التى أكد فيها أوسكار لويس على أن طبيعة المجتمع الفقير تتميز بيئته فيزيقية متأخرة وإسكان غير مناسب ومزدحم إلى جانب تدهور البيئة الأساسية والاعتماد على الأعمال الهامثية والصفات السيئة للأسرة، مثل: هجرة الآباء-

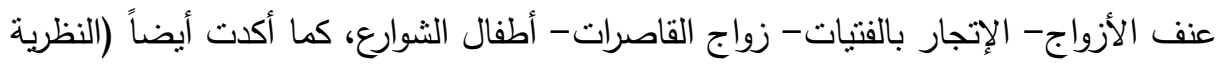
الهامشية) على نفس فكرة أن الفئات الفقيرة التى تتنمى إلى طبقة اجتماعية مجهولة في بيئة

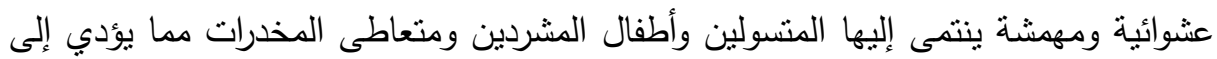

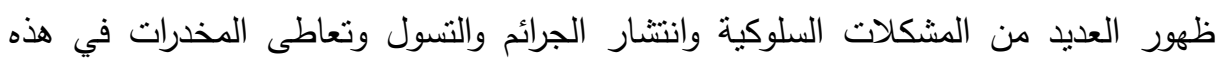

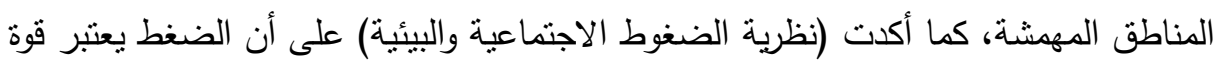

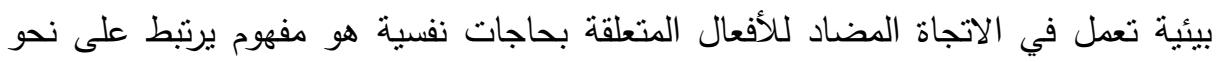

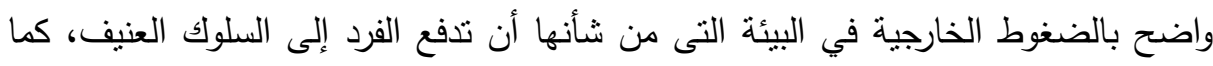
أكدت (نظرية النسق الأيكولوجي) على تأثر الطفل بالبيئة الفيزيقية من حوله فهو يتأثر

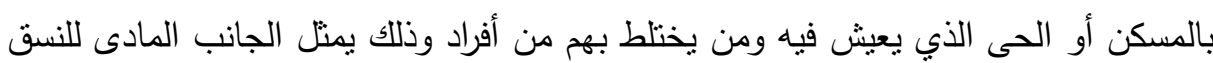
الأيكولوجى، كل ذلك ينعكس على الطفل وسلوكه مما قد يؤدي به إلى ممارسة العنف

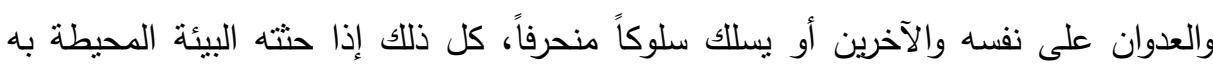
على ذلك. (•) نص الفرض الخامس: توجد علاقة ارتباطية بين الظروف البيئية القاسية (التدهور البيئى) وخروج الطفل إلى الثشارع. جدول(آ): يوضح العلاقة الارتباطية بين التذهور البيئي وخروج الأطفال إلى الثارع

\begin{tabular}{|c|c|c|}
\hline \multicolumn{2}{|c|}{ خروج الأطفال إلى الثارع } & \multirow{2}{*}{ التدهور البيئى } \\
\hline مستوى الدلالة & معامل الإرتباط & \\
\hline 9 . .,. د دالة & $\left({ }^{(* *)} \cdot\right.$, , $\ 7 \wedge$ & بيئة المسكن \\
\hline ع •., • دالة & $\left({ }^{*}\right),, r \neg \varepsilon$ & بيئة المنطقة \\
\hline سا, · غير دالة & $\cdot, 777$ & مشكلة المخلفات \\
\hline سا, · غير دالة & $\cdot, 1 \wedge r-$ & مشكلة التلوث \\
\hline r . . , • دالة & $(* *)$, , oro & الجانب الجمالى للبيئة \\
\hline r •, • دالة & $(*),, r \vee \leq$ & الدرجة الكلية لإستنيان التدهور البيئى \\
\hline
\end{tabular}


من الجدول السابق يتبين وجود علاقة ارتباطية ذات دلالة احصائية بين هروب الأطفال

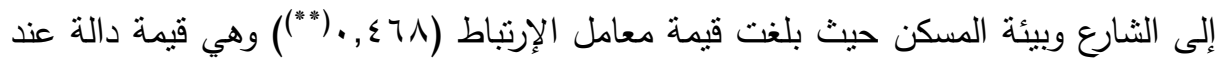

$$
\text { مستوى معنوية (9 ( ., ·)). }
$$

كما يوجد علاقة ارتباطية ذات دلالة احصائية بين هروب الأطفال إلى الثارع وبيئة

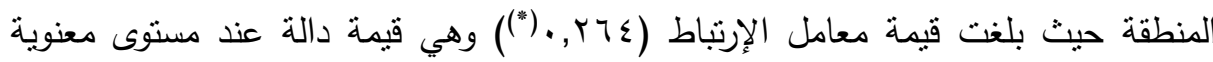

كما تبين وجود علاقة بين الجانب الجمالى للبيئة وهروب الأطفال إلى الثارع حيث

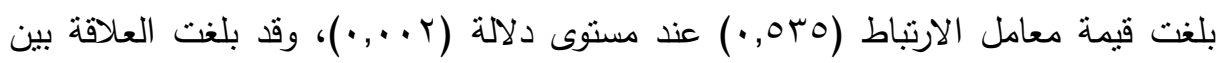
الدرجة الكلية لمقياس التدهور البيئى وخروج الطفل إلى الثارع وذلك عند مستوى دلالة

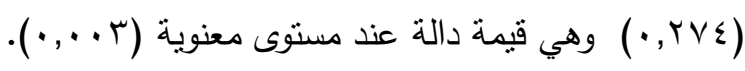
تفسير نتائج الفرض الرابع: يتضح من نتيجة هذا الفرض وجود علاقة ارتباطية بين التذهور البيئي والظروف القاسية التى يعيش فيها الأطفال وخروجهم إلى الثارع وذللك على الدرجة الكلية لمقياس التدهور البيئي، وقد أكدت عدة دراسات على ذلك من أهمها دراسة (عباس الكاس

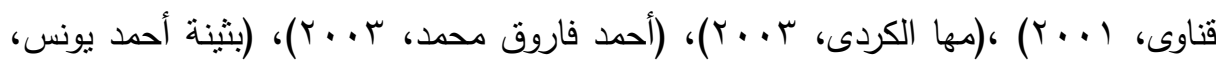

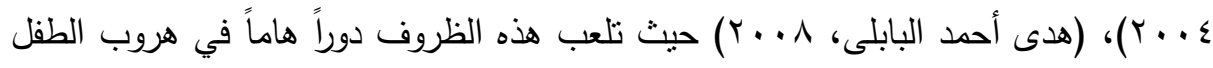

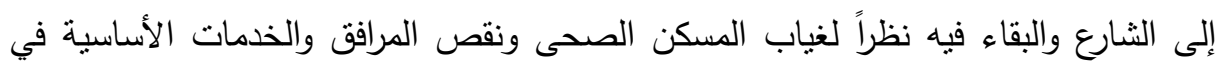

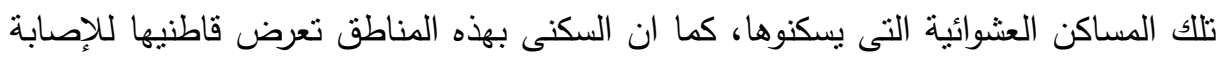

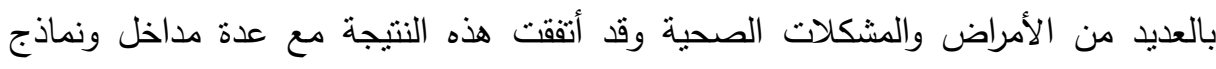

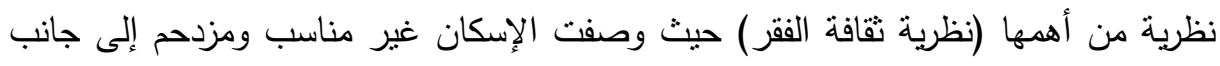
تذهور البيئة الأساسية والإعتماد على الأعمال الهامثية وغيرها، بالإضافة إلى ما ألى أكدته

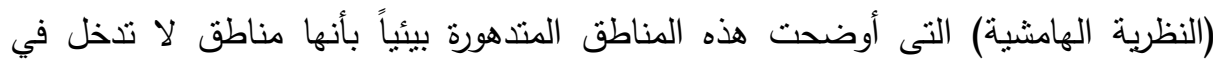

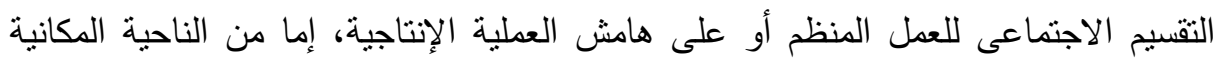

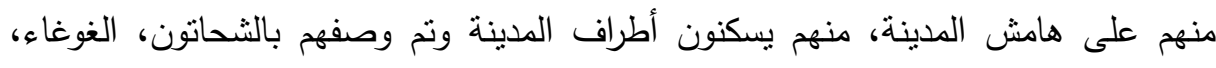

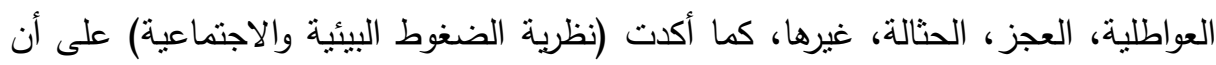


من أهم أنواع الضغوط التى تميز هذه المناطق المتدهورة بيئياً هي البيئة الفيزيقية المتدنية والمتهالكة والضوضاء والإزدحام والكوارث الطبيعية كالزلازل والبراكين ومختلف أنواع التلوث (ماء- هواء- تربة) وقد أنثارت نظرية الضغط البيئي إلى أن الضغوط البيئية كالازدحام

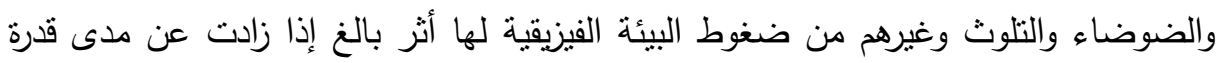
الإنسان على إحتمالها، حيث تؤدي إلى النزوح للعنف، كذللك (النموذج الإيكولوجى متعدد

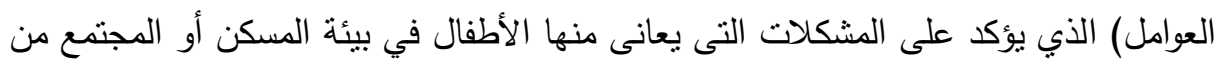

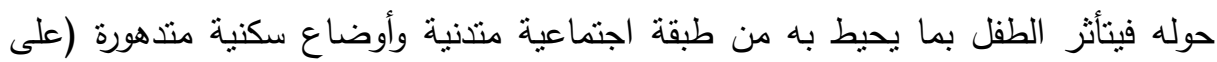

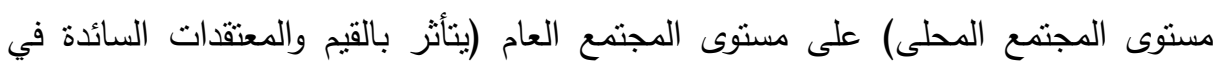

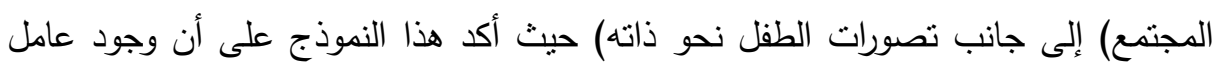
واحد فقط أو أكثر منهم يقلل من احتمالات تعرض الطفل لسوء المعاملة والإهمال ونتيجة لذلك

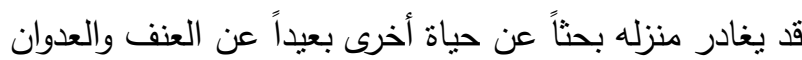

\section{الميوكيانص}

ا - اتخاذ قرارات سليمة وإيجابية بشأن ظروف أطفال الثوارع واحتباجاتهم وتوفير الخدمات الأساسية لهم (مثل: الغذاء الصحى والملبس الجيد، الدورات الدراسية، محو الأمية واكمال

$$
\text { التعليم، الإهتمام بالصحة، والدعم النفسي ). }
$$

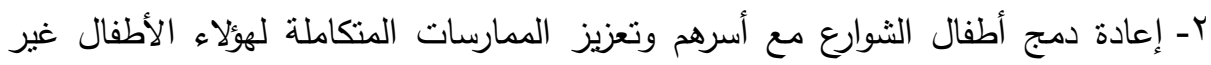
القادرين أو الذين برفضون العودة إلى منازلهم.

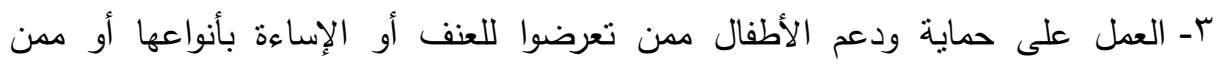
يتتاولون المخدرات من قبل صانعى القرار وخلق استراتيجيات للتكيف.

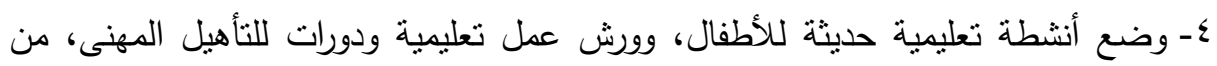
أجل تسهيل إلحاق أطفال الثوارع في النظام التعليمي العام، وتعليمهم حرف تقيدهم فئ ونى العمل والإبتعاد عن التسول والأعمال الهامشية الآخرى. 0- نوفير برامج إرشادية للمقبلين على الزواج وخاصة لدى من ينتمون للمناطق العشوائية حول

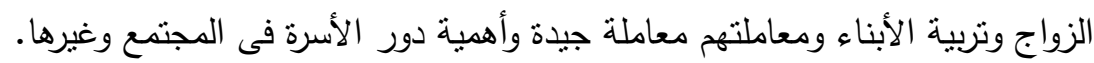

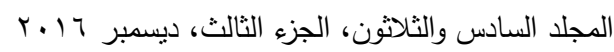


ا- التخطيط العلمى لمواجهة بعض المشكلات البيئية فى المناطق المتدهورة بيئياً، مثل مشاكل

$$
\text { المرافق العامة أو الخدمات العامة. }
$$

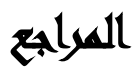

أحمد فاروق محمد صالح(ب . . ب): تصور مقترح لدور الخدمة الاجتماعية في مواجهة ظاهرة

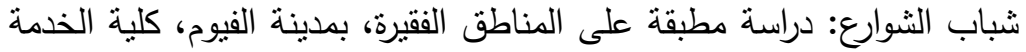
الاجتماعية، جامعة القاهرة

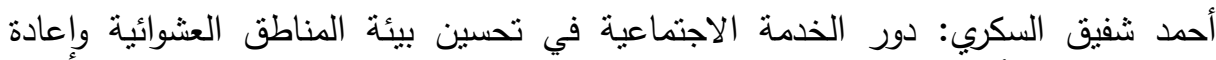
تأهيلها، المؤتمر العلمى السنوى الثامن عشر، كلية التية الخدمة الاجتماعية، جامعة

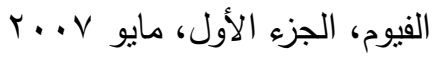

المجلس القومى للطفولة والأمومة، مشروع استراتيجية حماية وتأهيل الأطفال بلا مأوى "أطفال

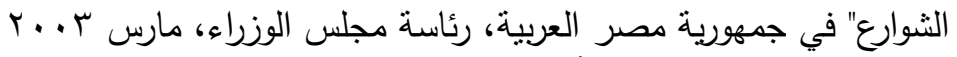

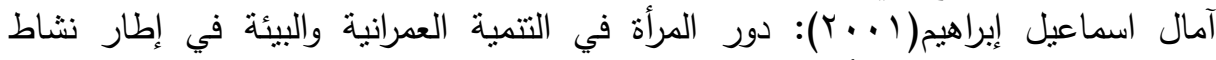

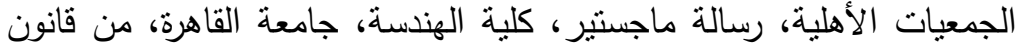

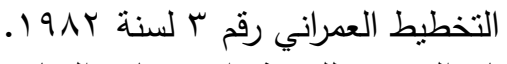

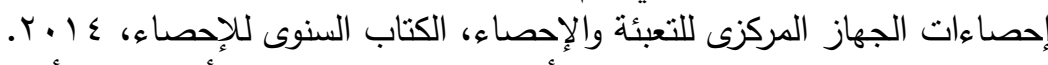

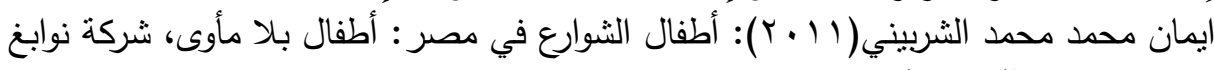

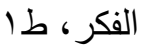

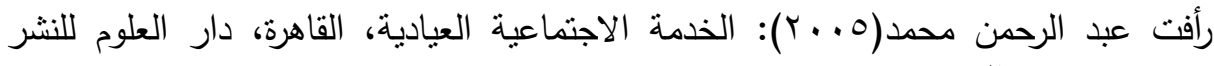
والتوزيع.

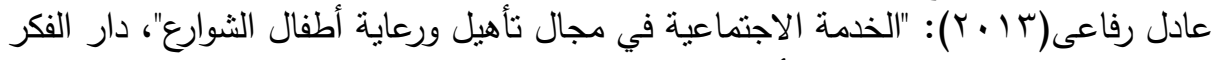

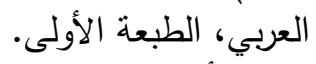

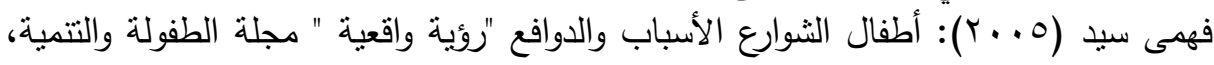

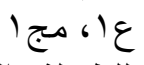

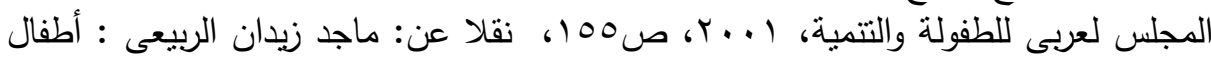

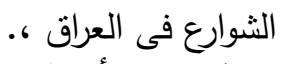

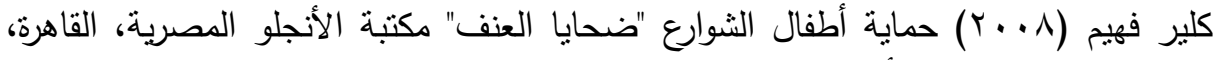

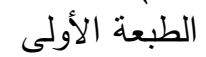

ماجدة السيد عبيد( . . ب): تعليم الأطفال المتخلفين عقلياً، دار صفاء للنشر والتوزيع، عمان،

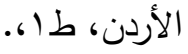




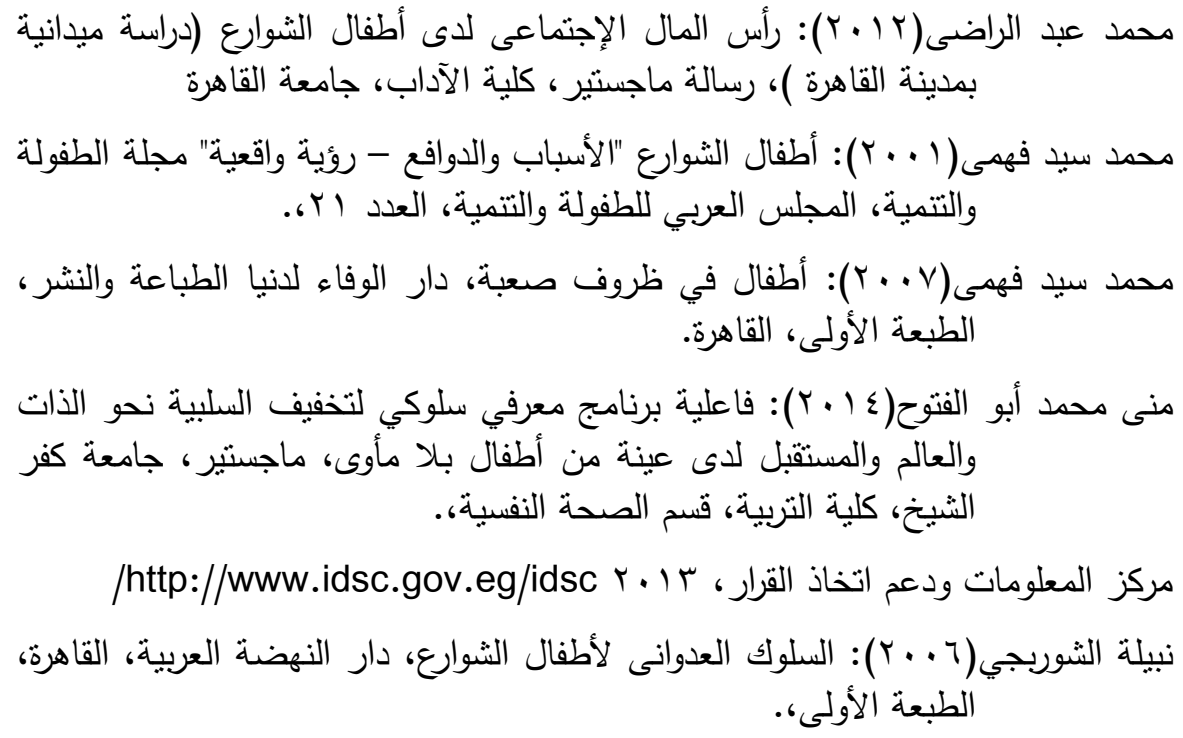

Chakraborty - Kabita, Visions: Street children, thoughts and ptepartons of the environment, Sociology - Ethpic - and Racial Studies, En vironmental - Sciences, vol 41-03, 2002, P. 703.

Marlene. G, Cooper, Joon Granue: lesser: clinical social work practice an integrated approach New York, person education, INC, 2005.

Kendall. P. Mahoney: cognitive behavioral therapies with youth Guiding, Journal of consuiting and clinical psychology vol. 61, 1996

Michael Kerfoot \& et. al (2009): Neglected, Abused, and Expoited children: The kyir street children project, journal of social welfare, vol. 18 (1), pp. 27-44.

Nerga \& Manning: "Incorporation Environmental Behavior Eithics and values into non formal environmental education progtams" the Journal of environmental education, vol 28, No. 2, 1997.

United Nation (1985): the Right child in the world. New York.

Zayfert Claudia \& Etal: cognitive behavioral therapy for PTSD: A case formulation Approach, New York, USA: Guilford press, 2006. 


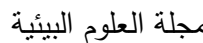

معهد الدراسات والبحوث البيئية - جامعة عين شمس البئ

\title{
A PROPOSED PROGRAM WITH COGNITIVE \\ BEHAVIORAL BACKGROUND FOR SOME TYPES \\ OF ENVIRONMENTAL BEHAVIOR MODIFICATION \\ OF STREET CHILDREN AT ENVIRONMENTALLY \\ DETERIORATED AREAS
}

[6]

\author{
Al- Atiq, A. M. ${ }^{(1)}$; Banhawy, H. S..$^{(2)}$ and Amer, Al-shimaa, B. ${ }^{(1)}$ \\ 1) ) Institute of Environmental Studies and Research, Ain Shams \\ University.2) National Center For Traslation.
}

\begin{abstract}
The Aim of the present research is to check the effectiveness of a proposed program to modify some of the patterns of environmental behavior among street children and applied to a sample of children in some of the reception of street children centers for the displaced from some environmentally degraded areas, and formed the sample of 60 children, (30) experimental group, (30) child of the control group, the researcher used the quasi-experimental method in the sample depending on the program to modify some patterns of environmental behavior and the use of behavioral and environmental attitudes scale as a way serve the goal of the program through applied to the children before and after the application of the program, in addition to the use of environmental degradation scale, scale appreciation personal children, have reached research into some of the results of the most important of which demonstrate the effectiveness of the program in modifying some of the patterns of environmental behavior in children, as well as the physical environment conditions play an important role in the exit of the street, as the study recommended a set of recommendations of the most important scientific planning to confront some of the environmental problems in degraded areas environmentally, such as the problems of 182

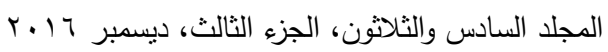


أحمد مصطفى العتيق وآخرون

public utilities or public services, the study of cases of street children and address them so as not to endanger them, along with the establishment of projects offer through which children who have dropped out of education needs with a vision to solve the physical and social problems for their families. 